\title{
The Dynamics of Venture Capital Contracts
}

\author{
Carsten Bienz ${ }^{\mathrm{a}, \mathrm{c}}$, FMG-LSE and CFS, \\ Julia Hirsch ${ }^{\mathrm{b}, \mathrm{c}}$, Goethe University Frankfurt and CFS \\ JOB MARKET PAPER
}

October 2005

\begin{abstract}
We analyze the degree of contract completeness with respect to staging of venture capital investments using a hand-collected German data set of contract data from 464 rounds into 290 entrepreneurial firms. We distinguish three forms of staging (pure milestone financing, pure round financing and mixes). Thereby, contract completeness reduces when going from pure milestone financing via mixes to pure round financing. We show that the decision for a specific form of staging is determined by the expected distribution of bargaining power between the contracting parties when new funding becomes necessary and the predictability of the development process. To be more precise, parties choose the more complete contracts the lower the entrepreneur's expected bargaining power - the maximum level depending on the predictability of the development process.
\end{abstract}

Keywords: venture capital, corporate governance, moral hazard, renegotiation, contract theory, empirical contract theory, contract econometrics JEL classification: G24, G32, D86, D80, G34.

\footnotetext{
${ }^{a}$ Carsten Bienz is a research associate at the Financial Markets Group - London School of Economics and a research fellow at the Center for Financial Studies, Frankfurt. This paper forms the first chapter of his PhD thesis at Goethe University Frankfurt. Address: R 409, Houghton Street, London WC2A 2AE, England UK. Tel:+44 (0) 20 78523521. E-mail: c.bienz@lse.ac.de

${ }^{b}$ Julia Hirsch is a PhD student at Goethe University Frankfurt. Address: Goethe University Frankfurt, Schumannstraße 60, 60325 Frankfurt am Main, Germany. Tel: +49 (0) 69 79822702. E-mail: jhirsch@wiwi.uni-frankfurt.de

${ }^{\mathrm{c}}$ This paper is part of a larger research cooperation between the Center for Financial Studies and KfW. It was presented at Goethe University Frankfurt, SITE-SSE and LSE, the GAEL-INRA Conference on Industrial Organization, the Econometric Society World Congress 2005 and the International Conference on Finance in Copenhagen, the 2005 meetings of the Verein für Socialpolitik, the Northern Finance Association and the 3rd RICAFE Conference. We would like to thank Renée Adams, Eric Berglöf, Mike Burkart, Jess Chua, Antoine Faure-Grimaud, Stefanie Franzke, Guido Friebel, Mariasunta Giannetti, Christian Laux, Mario Pagliero, Per Strömberg, Uwe Walz and Volker Zimmermann (KfW) for valuable comments. Finally, we would also like to thank all KfW employees at KI for their support and especially Andreas Weber (KfW) for his help. All errors remain ours. Carsten Bienz gratefully acknowledges financial support by German Research Foundation (DFG).
} 


\section{Introduction}

Traditionally, young innovative firms have difficulties in obtaining capital. Reasons are the high risk, the severe asymmetric information issues as well as the various moral hazard problems that come hand in hand with such an investment. As the venture capital industry succeeded in developing several mechanisms to cope with the mentioned problems, it has become essential for the financing of these firms ${ }^{1}$. In this paper, we look at one major mechanism: staging.

Staging implies that not all the capital necessary to finance the project is paid out up front but in several tranches. The exact conditions for these tranches vary. To be more specific, there exist two different forms: round financing and milestone financing. Round financing means that every new tranche is negotiated separately when the venture needs further funding; milestone financing requires that exact contingencies that the firm has to achieve to obtain new funds are fixed in the initial contract. Therefore, the decision for one specific mode of staging is also a decision for or against contract completeness which then determines the impact of renegotiation on future financing conditions.

Against this background, the aim of the present paper is twofold. First, we examine the determinants of staging in general. Second, we analyze the contracting parties' choice of one specific form of staging. We show that the decision for staging per se is determined by the degree of uncertainty and asymmetric information whereas the use of a specific form of staging is determined by the expected distribution of bargaining power between the contracting parties when new funding becomes necessary and the predictability of the development process.

To our knowledge, there only exist three important empirical studies on staging. First, Gompers (1995) [11] looks at the structure of staged investments. He focuses on the determinants of funding size and funding duration for round financing but refrains from analyzing the determinants for one specific form of staging. The same is true for Kaplan and Strömberg (2003) [15] and (2004) [16] who examine the determinants of the strength of both round and milestone financing separately. In this paper, we go beyond the existing empirical research by empirically modelling the choice of a specific form of staging. Thereby, we focus on the impact of renegotiation of future financing conditions on the initial contract design. We are not aware of other empirical papers testing this issue. However, Guasch et al. (2003) [13] and Ricard (2005) [22] present studies that focus on the decision for renegotiation given actual contracts. The former estimate a model of renegotiation for South-American procurement contracts while the latter considers contract renegotiation in the Spanish movie industry. Thus our approach is complementary to theirs.

\footnotetext{
${ }^{1}$ For a more detailed introduction to venture capital, see for example Gompers and Lerner (1999) [12].
} 
Moreover, the majority of the growing empirical literature on venture capital, including the three previously mentioned studies on staging, is based on US data. Important exceptions are, for example, Kaplan et al. (2003) [17] whose study is based on a set of 23 countries, as well as Cumming (2002) [8] and Bottazzi et al. (2004) [4] for the European market. The most important exhaustive study for the German market is the one of Bascha and Walz (2002) [2] that is based on survey data and analyzes security choice.

Against this background, the paper attempts to further reduce the existing gap of empirical research for venture capital industries outside the US by using a data set based on the German market. More importantly, contrary to existing studies about the German market, the underlying data set exhibits unique characteristics. First, the data set (a proprietary one from KfW) constitutes a random sample of all VC projects supported by KfW in Frankfurt, Germany. As KfW is involved in a substantial part of all German venture capital investments, it is a representative sample of the German venture capital industry. Second, it covers both boom and bust periods as the data range from 1991 until 2004. Finally, contrary to the majority of empirical studies, the data set is not based on survey data but the information was directly gathered from the contracts. To be more precise, it is based on all major documents concerning a specific deal, i.e. the business plan, the balance sheet, the term sheet, the shareholder's agreement as well as additional agreements.

The rest of the paper is organized as follows. The next section reviews the theoretical literature; the third section describes the underlying data set and presents descriptive statistics that characterize the venture capital industry in Germany. In the fourth section, we present empirical results. Section five concludes.

\section{What does theory tell us?}

In this section, we summarize the theoretical literature related to staging proceeding in two steps: while the different forms of staging - milestone and round financing - are analyzed in subsection 2.2, in the next subsection, we discuss the determinants of the decision for staging in general.

\subsection{Why do we use staging?}

Staging implies that some of the funds deemed necessary for the firm to complete its project are withheld. This mechanism has three major implications.

First of all, as not all capital is provided up front, staging implicitly gives the investor the right to decide about the continuation or liquidation of the firm. This exit option for the investor saves resources because infeasible (negative NPV) projects are identified 
and liquidated early on (see Hellmann (1994) [14]). Obviously, this advantage is the more pronounced the higher the existing ex ante uncertainty about the profitability of the project.

Second, in an asymmetric information context, staging can be interpreted as a signaling mechanism. Staged high quality firms face a low risk of liquidation in comparison with low quality firms whose liquidation risk is especially high. Thus an entrepreneur with private information about his firm's quality is able to use staging as a signal of firm quality. This issue is modelled by Dessein (2004) [10]. He models how a transfer of control to the investor serves as a signal of firm quality and congruence of objectives between the investor and the entrepreneur. Moreover, he shows that investor control is increasing in the ex ante information asymmetry and in the ex post uncertainty about the project. One possibility of implementing investor control in this model is by short-term financing. However, short-term financing can be interpreted as staging. Thus staging is the better, the higher the degree of asymmetric information ex ante and the more difficult future monitoring ex post.

Third, staging can act as a commitment device for the entrepreneur not to renegotiate the initial contract. This effect does not depend on the liquidation risk related to staging but rather on the fact that injecting less capital at the beginning of the relationship implies less sunk capital and consequently limited renegotiation possibilities for the entrepreneur. Neher (1999) [18] precisely models this mechanism. He shows that the entrepreneur cannot credibly commit to work and not to renegotiate if the venture has no collateral and the only asset is the entrepreneur's human capital itself. Furthermore, he points out that the hold-up problem can be solved by staging as the stepwise provision of capital coincides with a gradual embodiment of the entrepreneur's human capital in the firm. Thus staging should be the more advantageous, the more crucial the entrepreneur's human capital for the success of the project and the less tangible the assets.

We summarize these arguments in the following hypothesis:

Hypothesis 1 The higher the uncertainty, the higher the degree of asymmetric information, the more difficult future monitoring, the more crucial the entrepreneur's human capital and the less tangible the firm's assets, the more probable is staging.

Staging, of course, has also serious shortcomings. First of all, staging may cause delays as entrepreneurs have to commit time to the negotiation process. This lag caused in implementing the project can induce additional costs such as retardation in the development process or in market entry, lost economies of scale or cost overruns. Certainly, these additional costs have to be outweighed by the benefits of staging. We think, however, that these costs can be disregarded as they can be minimized by optimally structuring the negotiation process. 
Second, Cornelli and Yosha (2003) [7] show that the entrepreneur may react to the prospect of early liquidation with an attempt to manipulate available information. This phenomenon, called window dressing, reduces the positive effects of staging and tends to be the more probable the softer the information available. This is exactly the case for firms for which the benefits of staging are the highest. Thus we cannot control for the underlying countervailing effects but only for the net effect of staging. This means that throughout all our tests concerning hypothesis 1 , we will have to take into account that we only measure the net impact of staging.

Finally, staging also changes the entrepreneur's incentives. This impact is ambiguous: on the one hand, the liquidation risk increases the entrepreneur's incentives and, in turn, the project's overall probability of success. Wang and Zhou (2002) [23], for example, show that the termination threat induces the entrepreneur to work harder in order to ensure further financing by the investor. Therefore, in their model, the effort level of the entrepreneur is always higher under staged financing. On the other hand, staging induces opportunistic behavior by the investor. This opportunistic behavior, in turn, reduces the entrepreneur's ex ante incentives. The negative incentive effect of staging must therefore be traded off against the above mentioned positive incentive effect. This trade-off is analyzed by Rajan (1992) [20], for example, who compares arm's length financing (i.e. upfront financing) and insider financing (i.e. staging). However, the extent of the negative effect crucially depends on the form of staging. Aghion et al. (1994) [1] point out that the underinvestment problem normally related to renegotiation (and therefore to staging) can be completely overcome by an adequate design of the renegotiation process ${ }^{2}$. If this is the case, the net incentive effect can never be negative and its size depends upon the form of staging. Then incentive effects should not have an influence on the decision of staging per se but rather on the choice of a specific form of staging as we will show in the next subsection.

\subsection{When do we observe what form of staging?}

In the last section, we discussed the advantages and disadvantages of staging per se. However, some effects of staging, and among these especially the incentive effect for the entrepreneur, crucially depend on the form of staging which is chosen.

To be more precise, as shown above, there exist two different forms of staging, namely round financing and milestone financing. With round financing, every new tranche is

\footnotetext{
${ }^{2}$ They show that only two conditions must be fulfilled in order to guarantee an efficient outcome: first, the initial contract must specify a default option in case renegotiation fails and second, it must assign all the bargaining power to one party. The default option is determined by the initial contract, especially by the covenants which attribute specific rights to the investor in certain circumstances.
} 
negotiated separately when the venture needs further funding ${ }^{3}$. With milestone financing, the initial contract determines exact contingencies that the firm has to achieve to obtain new funds. Provided that the milestones are reached, the VC has the contractual obligation to release the funds to the firm ${ }^{4}$. Examples for such contingencies are the amount of revenues realized, the number of patents filed or the development of prototypes. Thus in this section, we analyze the disadvantages and advantages of these two forms in order to identify the determinants of a particular choice.

Firstly, milestone and round financing differ with respect to the degree of ex post flexibility and ex ante inefficiency. Whereas round financing offers more ex post flexibility, one obvious advantage of milestone financing is that it excludes renegotiation. Therefore, it prevents hold-up by the investor what eliminates the ex ante inefficiency caused thereby. This solution mechanism is modelled by Nöldecke and Schmidt (1995) [19], for example. In their model, the under-investment problem is overcome if the parties write a simple option contract that is very closely related to milestone financing: the entrepreneur has the right but not the obligation to exert certain effort levels and reach the specified milestones $^{5}$. If the milestones are reached, the investor must pay out the next tranche of capital as determined in the initial contract. If the milestones are not reached, the default point is specified by the action chosen by the entrepreneur, i.e. the result achieved. If the difference between the two cases is larger than the entrepreneur's effort costs, high effort becomes worthwhile. So milestone financing is the more profitable, the more pronounced the negative incentive effect due to possible hold-up by the investor.

In a similar way, Bigus (2002) [3] points out that the hold-up problem is the less pronounced, the smaller the loss of the entrepreneur when the relationship ends and a new investor must be found ${ }^{6}$. This means that the advantage of milestone financing increases with a decline in the entrepreneur's outside financing option.

Secondly, Cuny and Talmor (2004) [9] raise another advantage of milestone financing, namely its greater ex ante flexibility: With milestone financing, one contract covers multiple states of the world simultaneously and thus claims need not to be priced fairly ex post but only ex ante, i.e. before knowing the outcome. This higher flexibility is especially valuable if there exists a pronounced heterogeneity of beliefs between the contracting parties or if particular states require different incentive mechanisms.

\footnotetext{
${ }^{3}$ Thus no further funding is also an option.

${ }^{4}$ However, if any of the predetermined conditions are not met, no further funding will take place unless both parties negotiate new terms.

${ }^{5}$ Note that the exercise of any standard option contract is followed by a guaranteed delivery, while in our case some residual uncertainty is required because otherwise the moral hazard problem becomes irrelevant.

${ }^{6} \mathrm{He}$ interprets his result by stating that the loss can be reduced by reenforcing patent protection as to avoid idea stealing by the investor. As in our data set, regulations are given, we focus only on the financing options.
} 
Thirdly, Cuny and Talmor (2004) [9] also mention another possible disadvantage of milestone financing. Milestone financing promises the whole investment (contingent on milestones) ex ante whereas with round financing, there exists only a commitment to finance the current investment round. This means that the investor's claim should be considerably larger under milestone than under round financing. If we assume pure equity financing, this implies a larger equity stake given to the investor and consequently, a smaller equity stake retained by the entrepreneur: the entrepreneur's incentives are reduced. Thus the larger the total investment, the larger the negative incentive effect due to milestone financing. However, this is only valid with pure equity financing when the VC's equity stake is fixed initially and any additional capital is paid into the firm's capital reserves. Albeit this construct is found in practice, other constructs that avoid this problem are also frequently found. Thus the magnitude of this issue is not quite clear.

A further obvious, but extremely important caveat with respect to the choice of the different staging forms is the feasibility aspect: round financing and milestone financing must be implementable. As concerns round financing, it may cause prohibitively high contracting costs for very short time intervals creating a lower limit for the minimum duration of each round. The availability and enforceability of adequate milestone may be even more crucial. Even though this question has been largely ignored in the mentioned theoretical discussion, it is of extremely high empirical relevance. There are only a few studies that explicitly consider the nature of signals available and their relation to contracts. Repullo and Suarez (2004) [21], for example, look at the optimal capital structure with staging and the influence of signal availability on contract design ${ }^{7}$. To sum up these arguments, we can state the following hypothesis:

Hypothesis 2 Given feasibility of both staging forms, round financing compared to milestone financing should be the more probable, the better the entrepreneur's outside financing option, the less pronounced the heterogeneity of beliefs between the contracting parties and the higher the total investment amount.

\section{The Data Set}

\subsection{Sample and Sample Selection Issues}

Our analysis uses a proprietary, hand-collected data set from KfW based on contracts between VCs and their portfolio firms. KfW has a unique position in Germany's venture capital market: being Germany's largest promotional bank, it supports innovative firms by promoting the investment of the VCs. Although, as concerns our sample, KfW never directly invests in any of the portfolio firms, it becomes indirectly involved in the venture

\footnotetext{
${ }^{7}$ See section 4.2 and subsection 4.3 .1 for details.
} 
capital deals in Germany. In order to obtain support from KfW, VCs had to apply by submitting the key details of their relationship with the portfolio firm, most notably, the term sheets, the business plans and the shareholder's agreements. By providing us with access to these documents, KfW gave us the unique opportunity to collect detailed information on the relationship between the $\mathrm{VC}$ and its portfolio firm based on actual contract data.

In order to reduce the very time-intensive task of collecting detailed information from the numerous documents to a manageable size, we drew a random sample of 300 portfolio firms ${ }^{8}$. We categorized each portfolio company into one of three classes with respect to their investment date (before 1998, between 1998 and 2000, and after 2000) and eight classes with respect to the program or program combination through which their VC investor was supported by KfW. This categorization was undertaken with the objective to achieve a balanced representation of the population. Table 1 gives an overview about our sample and the support programs considered. Unfortunately, the data for 10 portfolio companies could not be evaluated. Therefore, our random sample finally consists of 290 portfolio companies that were financed in 464 investment rounds between 1991 and 2004.

We are confident that we do not have any major bias in the selection of our sample for two reasons. Firstly, as we were responsible for the sample selection process ourselves, we ensured that no selection bias occurred via the provider of all our documents (KfW) by drawing a random sample of all VC financed portfolio companies supported by KfW. Secondly, KfW supported a large proportion of the population of all investments realized by the German venture capital industry in the time period under consideration ${ }^{9}$. This means that we have a representative sample of the German VC industry. One obvious selection bias which we were not able to circumvent is the fact that we are concentrating on one particular geographic region (Germany) and the associated venture capital market. To a lesser degree this is true for the time period. We take all this into consideration by interpreting our data sample as the description of a situation of a young and evolving venture capital market.

As concerns the process of data collection, for each investment round, we evaluated the company's balance sheet data and its business plan to get information with respect to the market position of the company and details about the financed project. Moreover, we took from the term sheet and the shareholder's agreement detailed information about the security design, the timing, conditions and syndication of the investment, control and information rights of the venture capitalists and exit covenants. We translated this

\footnotetext{
${ }^{8}$ We draw this sample out of the population of all portfolio firms that were financed by venture capitalists which, in turn, were supported by KfW via one of the programmes mentioned in table 1 .

${ }^{9}$ According to the German Venture Capital Association ([5] and [6]), there were 11854 seed, start-up and expansion deals by its members in the relevant time period; KfW supported almost 7100 deals of potential members. This implies a market coverage of approximately $60 \%$.
} 
information into quantifiable variables. Finally, we complemented the data set with information about the venture capitalist supported by KfW. Overall, we gained a detailed picture of the control and information rights embedded in these contracts as well as of the characteristics of the entrepreneurial firm, the founder(s) and the VCs involved.

As usual in this type of studies, we were confronted with the problem that not always all data were available. Thus the number of observations may vary depending on the variable studied. Typically, the amount invested and valuations were the most reliable variables whereas information on staging or investment memoranda were sometimes missing. Still, we do not see a systematic selection bias problem because there are several reasons for missing data. On the one hand, data may be missing for very young firms but, on the other hand, we often had also the most exhaustive term sheets for these firms.

\subsection{Variable Descriptions}

In what follows, we describe the data set in more detail and introduce the variables necessary for our regressions. Please note that all balance sheet data as well as exogenous factors such as the state of product development or the degree of asymmetric information is information that is known to the $\mathrm{VC}$ and the entrepreneur before they sign the contract.

\subsubsection{Firm characteristics}

We have information about the project and the respective portfolio company. The variable AGE represents the age of the firm when the corresponding financing round is closed. Moreover, we observe the firm's industry: LIFE SCIENCES, INTERNET, IT/TELECOM, TRADITIONAL HIGH-TECH and OTHER INDUSTRIES are all dummy variables that indicate the project's industry. GROWTH INDUSTRIES is a dummy variable that indicates whether the firm is active in an industry with high growth potential, that is whether it corresponds to one of the three first mentioned industries or not.

Furthermore, we observe the firm's development stage in each financing round. First, we have information about the firm's development stage as defined by the German Venture Capital Association. We distinguish seed and start-up firms on the one hand, and expansion and later stage firms on the other hand: the dummy EARLY STAGE indicates whether the firm belongs to the first group or not. Second, we have balance sheet information from the year preceding the closing date of the corresponding financing round. We know whether the firm has any revenues (if this is the case, the dummy REVENUES takes value one) and we observe the fixed asset ratio (FAR) that indicates the ratio of fixed assets to balance sheet total ${ }^{10}$. Third, we have information about the firm's achievements.

\footnotetext{
${ }^{10}$ As we have many missing values in our sample, we adopt the following procedure. For all firms in a first financing round, with an age of less than one year and an investment phase of seed or early, we set
} 
We know whether the firm has finished its product tests; whether it already has a finished product; whether the firm holds any patents or if it even has reference customers. We define a dummy named PATENTS taking value one if the firm holds any patents or its patents are pending when the financing round was closed. In addition, we construct two types of indicator variables that we deem necessary to test our hypotheses. First, we create a proxy for the degree of asymmetric information between both parties named AI. We think that the degree of asymmetric information heavily depends upon the amount of verifiable information that is available for the project. Thus we create a categorical variable by summing up four dummy variables which describe, in our opinion, essential steps in reducing information asymmetry: the dummy AUDITED BALANCE SHEET that indicates whether the balance sheet has been audited or not, the dummy FINISHED PRODUCT which signals the existence of a product, the dummy REFERENCE CUSTOMERS that indicates the existence of any reference customers and finally, the dummy BREAK EVEN that takes value one if the firm has reached its break-even point. While we could have included more factors in this definition, one problem we have is that we loose observations due to missing data. We thus strive for an optimal balance between measuring the degree of asymmetric information and data availability. Additionally, we define a variable which measures the relative degree of asymmetric information named RAI. This variable is aimed at correcting for the developmental aspect inherent in the AI variable. It is defined as the ratio of the degree of asymmetric information of the respective firm relative to the average degree of asymmetric information of all firms in the respective development stages (early stage, expansion, later stage). Second, we construct two measures that capture the current position of the firm in its development process: MARKET ENTRY takes value one if the firm has both a finished product and revenues. This proxy indicates that the introduction of the product in the market has successfully taken place. The dummy PRODUCT DEVELOPMENT takes value one if the product development process is just starting, i.e. if there does not exist a finished product, there do not exist any reference customers and product tests have not been successfully completed yet.

Finally, we observe whether the firm already received financing from banks or other VCs prior to the observed investment round. More concretely, we define a dummy OUTSIDE FINANCE that takes value one if the portfolio company has received bank, angel or other $\mathrm{VC}$ finance before the first round of $\mathrm{VC}$ financing we are looking at or if $\mathrm{VC}$ financing takes (or has taken place before) via a syndicate of different VCs. We think that both facts weaken the (lead) VC's informational advantage over other investors and thus ameliorate the entrepreneur's outside financing option.

the fixed asset ratio to zero. If we lack information for higher rounds, we use the same ratio as in the round before. If this ratio is not available, we code both as missing values. Additionally, we do not resort to the preceding round in the case of second rounds where we coded the first round data to be zero. 


\subsubsection{VC, entrepreneur and investment characteristics}

Second, we have information about the VC, the entrepreneur and the investment characteristics. We classify each VC according to his type into three categories named INDEPENDENT VC, PUBLIC VC and OTHER VC. The latter category includes both bankdependent and corporate $\mathrm{VCs}^{11}$.

Moreover, we have information about the entrepreneurs running the portfolio firm. We know if any of the founders has a $\mathrm{PhD}$ or higher degree of education (then, the dummy variable RESEARCH DEGREE takes value one), we observe whether any of the founders has a background in engineering or natural sciences (in this case, the dummy variable SCIENCE BACKGROUND takes value one) and we know whether we face a repeat entrepreneur, i.e. someone who has already run a firm (this is captured by the dummy variable REPEAT ENTREPRENEUR). In order to account for the value of the entrepreneur's human capital within the firm, we construct the variable E EXPERT. As we know that the entrepreneur's role is crucial for the technological development of the product, we take into account both the qualification of the entrepreneur and the need of expertise by the firm when constructing the variable. More concretely, the variable takes value one if the firm belongs to a high-tech industry, the firm's product has not finished any tests (i.e. the firm strongly needs the entrepreneur's contribution) and if the entrepreneur holds a research degree (i.e. the entrepreneur is highly qualified).

Finally, we have information about the investment itself. We observe the year when the financing round is closed and define three time dummies. PERIOD 1 takes value one if the financing round is closed during the early period of relatively low venture capital activity, namely before 1998, PERIOD 2 if it is closed during the boom, i.e. between 1998 and 2000 and PERIOD 3 if it is closed after 2000 - a period of relative decline and reorganization of the venture capital industry. In addition, we observe the total amount invested, the financing instrument used and the timing of the investment. In order to control for the total amount of capital necessary to finance the project, we construct a further proxy variable. We assume that each firm's balance sheet has to reach a certain minimum threshold before the firm can be taken public. This size is the average balance sheet of all firms in Germany's "Neuer Markt" prior to their IPO in the five mentioned industries $^{12}$. The variable EBS (expected balance sheet) is then defined as the difference between the average balance sheet of the public firms in the respective industry and the current balance sheet of the firm we are studying and is again normalized by the average balance sheet ${ }^{13}$.

\footnotetext{
${ }^{11}$ We also include the business angels in our sample in this category.

${ }^{12}$ We thank Stefanie Franzke for giving us access to her data on IPOs on the "Neuer Markt".

${ }^{13}$ For around 20 firms we observe this value to be negative. Our theory says nothing about this type of firms. Therefore, we coded them as missing values in our regressions.
} 


\subsubsection{Staging: Definition and Measurement}

As the aim of this paper is to analyze the determinants of staging and its different forms, it is important to exploit all the available information related to staging. Therefore, in a first step, we define a dummy variable, named STAGING, that takes value one if the project is financed in several steps and zero otherwise. This means that STAGING takes value one whenever one of the different staging forms can be observed. These are captured by two dummy variables: ROUND takes value one if staging is made in several independent rounds and MILESTONE if future capital is contingent on specific known milestones.

To be more precise, the variable MILESTONE takes value one if at least $20 \%$ of the investment is dependent on the achievement of predefined milestones. The variable ROUND takes value one whenever we observe a further financing round. Additionally, it takes value one when we know that the current round does not finance the project until its break-even. The latter information is taken from the VC's investment memoranda. This construction has two important implications. First, we even have information for the most recently financed projects what allows us to circumvent two major econometric problems: truncation and autocorrelation between the financing rounds. Second, the probability of round financing may be overestimated (and therefore, the probability of staging) as the above definition also includes rounds where staging was not expected in the beginning but occurred "by accident". The problem we faced was that it is quite difficult to distinguish between the fact that further financing rounds were really unexpected or were just not mentioned in the original contract.

We also define three subcategories: PURE MILESTONES, PURE ROUNDS and MIXES. PURE MILESTONES takes value one if milestone financing occurs and we know that no round financing takes place. Analogously, we define PURE ROUNDS. MIXES takes value one if we know that milestone and round financing are used simultaneously. Finally, we consider four categories of milestones: financial milestones, product milestones, firm specific (other) milestones and different mixes of these types of milestones.

\subsection{Descriptive Statistics}

In what follows, we want to give a more detailed overview about the sample. Therefore, in a first step, we present some basic descriptive statistics. The average amount invested per financing round is about 5.4 million euros and the portfolio companies are in average 5.08 years old when they receive $\mathrm{VC}$ financing for the first time. The medians are considerably smaller (1.3 million euros and 2 years), an indication for outliers. At this point, one can already infer that the percentage of early stage financing is quite high in our sample. Indeed, $11.3 \%$ of the financing rounds correspond to seed financing and $61.5 \%$ to start-up financing whereas only $20.7 \%$ of the financing rounds are related to expansion and $6.6 \%$ 
to later stage firms ${ }^{14}$. The portfolio companies are active in a broad range of industries: $20.7 \%$ in the field of life sciences, $36 \%$ in the sector of IT, telecommunications and software development, $9.7 \%$ belong to the internet sector, $19.6 \%$ are active in traditional high-tech industries and $14 \%$ could not be classified in neither of these sectors but are active in rather less $R \& D$ intensive branches.

Second, we want to characterize the different types of financial instruments used (see table 2). As a broad range of different combinations of financial instruments achieves the same allocation of cash-flow and control rights, it is important to analyze these instruments properly. Therefore, we classify each financial instrument used in a single financing round along five characteristics: upside cash flow rights, downside protection, change of control, cash flow rights at exit and voting rights. This classification procedure allows a better interpretation of the securities used and guarantees better comparability. In a second step, we distinguish four main categories (pure equity, pure debt ${ }^{15}$, debt-equity mixes and convertibles) and nine subcategories. Thereby, the more detailed classification takes into account the existence of liquidation preferences or the extent of the debt component in debt-equity mixes. We see that whereas debt and different types of equity play an important role (23\% and $29 \%$ respectively), debt-equity mixes are the most frequently used type and occur in $38 \%$ of all financing rounds. Only $8 \%$ of all firms are financed by convertible instruments.

Last but not least, table 3 describes the observed staging behavior in our sample. Staging is used in $70 \%$ of the analyzed observations; pure rounds are the most frequently used form (59\%), followed by mixes (24\%) and pure milestones (17\%). There also seem to be differences in the staging behavior across time and VC types. As shown in table 3, there is a slight decline in the use of staging during the boom period - this may be attributed to the reduced bargaining power of the VCs due to the high amounts of capital chasing few deals in that time period - and an increase in period 3 slightly beyond the level of period 1. Interestingly, when looking at the different staging forms, we recognize more pronounced changes. While in period 1 only $7 \%$ of staging is in the form of pure milestones, $7 \%$ is in the form of mixes and $86 \%$ is in the form of pure rounds, the composition changes dramatically in the third period: staging in the form of pure milestones increases up to $24 \%$, staging in the form of mixes increases to $29 \%$ and staging in the form of pure rounds decreases to $47 \%$. As concerns the behavior of the different VC types, we see that VC types differ in both the implementation of staging per se and the use of the different forms of staging. On the one hand, independent VCs use staging more often than other VC types which in turn use staging more often than public VCs. On the other hand, independent

\footnotetext{
${ }^{14}$ These percentages refer to the financing rounds for which we have available data for the respective criterion.

${ }^{15}$ Debt is actually subordinated debt, thus it is only senior to the equity in the firm.
} 
VCs use rounds in more than half of all staged firms, but use relatively more mixes than pure milestones; public VCs use rounds in more than half of all staged firms, but they use relatively more pure milestones than mixes; and finally, other VC types use rounds in $77 \%$ of all staged firms and, similarly to public VCs, they use more pure milestones than mixes.

\section{Empirical Evidence}

\subsection{The determinants of staging}

We begin by evaluating hypothesis 1 that refers to the determinants of the staging decision. In a first step, we discuss the instrumentalization of this hypothesis before presenting the descriptive statistics and the results of the univariate probit models. We conclude by discussing the robustness of our results and their implications.

\subsubsection{Instrumentalization of the hypothesis}

Hypothesis 1 can be divided into two parts. The first part states that the higher the uncertainty, the higher the degree of asymmetric information and the more difficult future monitoring, the more probable is staging. The second part refers to the positive causal relationship between the importance of the entrepreneur's human capital and the staging decision.

Therefore, our empirical strategy can be based on the following model:

$$
\text { Staging }_{i}=f_{i}(\text { Uncertainty, Asymmetric Information, Human Capital, Controls })+\epsilon_{i} \text {, }
$$

where

$$
\text { Staging }_{i}= \begin{cases}1 & \text { if firm } \mathrm{i} \text { is staged } \\ 0 & \text { if firm } \mathrm{i} \text { is not staged }\end{cases}
$$

While finding adequate controls is relatively straightforward, differentiating between uncertainty, asymmetric information and firm development in general poses a relatively large challenge. Several potential indicator variables capture different aspects of uncertainty and asymmetric information like the firm's age, the early stage dummy, the revenue dummy or the AI variable ${ }^{16}$. However, none of these variables captures all different facets of uncertainty and asymmetric information and all of them include a "developmental aspect". This means that all indicator variables compare the firms along their development path but not from a cross-sectional perspective. Unfortunately, such a cross-sectional view cannot be

\footnotetext{
${ }^{16}$ Note that these variables are indeed apt to control for the mentioned aspects because further characteristics of older firms which are crucial in other contexts - like the availability of internal funds - are irrelevant for the large majority of firms in our sample.
} 
implemented for the majority of these variables ${ }^{17}$. We try to cope with this limitation for the AI variable by using the RAI variable instead. However, this variable must be handled with precaution as some of its components are fundamentally linked to the development stage of the firm. This means that the differences between the firms of one comparison group (e.g. all early stage firms) are quite small resulting in a relatively low information content of the variable.

Thus we face a set of possible proxy variables that are quite heterogeneous in the economic effects they capture but are certainly not mutually exclusive as they are partial substitutes for each other. This view is also reconfirmed by the correlations of these variables (see table 5). As we face the econometric problem that we cannot include all proxies simultaneously into the regression, we separately run the same standard specification for each proxy variable to ensure the robustness of our findings.

\subsubsection{Descriptive results}

The descriptive results are shown in table 4. As we can see, the descriptive statistics broadly confirm the first part of hypothesis 1: staged firms are significantly younger, have lower revenues, are more probable to be early-stage firms and exhibit a higher degree of asymmetric information. In fact, all four components of AI ( AUDITED BALANCE SHEET, FINISHED PRODUCT, REFERENCE CUSTOMERS, BREAK EVEN) significantly differ between staged and non-staged firms. Interestingly, the means of the RAI variable do not significantly differ between staged and non-staged firms. This implies that developmental aspects seem to play a crucial role. Though, given the above discussed limitations of our RAI variable, this result does not mean that "pure" asymmetric information problems are irrelevant.

The second part of hypothesis 1 is only partly confirmed. Table 4 shows that neither the fixed asset ratio nor the majority of the human capital indicator variables significantly differ between staged and non staged firms. Only the research degree dummy is significantly higher for staged firms.

Finally, there are several control variables which differ significantly. There are significantly more life-science and internet firms and significantly less traditional high-tech firms and firms of other industries among the staged firms. This may be explained by the fact that the former industries are related to a higher degree of uncertainty or to the fact that they are more research-intensive and that therefore the entrepreneur's human capital is more important. Moreover, there exist significant differences with respect to the time periods and the VC types.

\footnotetext{
${ }^{17}$ Because the developmental aspect is completely inherent to these variables.
} 


\subsubsection{Regression results}

In this subsection, we present the results for hypothesis 1 based on univariate probit regressions with error terms clustered at the firm level. The results corresponding to the first part of hypothesis 1 can be found in table 6 . We find broad support for this first part, namely the impact of uncertainty and asymmetric information. More specifically, as outlined in subsection 1, we successively include all our different proxy variables and get the following results: AGE is negative and significant at the $5 \%$ level, showing that the older the firm, the less probable becomes staging; EARLY STAGE is positive and significant at the 1\% level indicating that the probability for staging is $19 \%$ higher for early stage firms; and finally, REVENUES is negative and significant at the $5 \%$ level. This means that the probability for staging is smaller for firms with revenues. In order emphasize the asymmetric information aspect, we use the categorical variable AI. The coefficient is significant at the 1\% level: the higher the degree of asymmetric information the more probable becomes staging. Using the components of AI on an individual basis yields further insights: in fact, the result seems to be driven by only one component of AI, namely BREAK EVEN which is significant at the $1 \%$ level. This already points out that developmental aspects seem to play a predominant role. In order to blind out this aspect and focus on "pure" asymmetric information, we subsequently include RAI in our regression: the coefficient is insignificant, however. We also get an insignificant coefficient for the expected sum of funding still necessary to bring the firm public (EBS) ${ }^{18}$.

It is also interesting to have a look at the control variables. Surprisingly, both the control variables for the different VC types and for the time periods are insignificant. The picture is different for the industry proxies though: LIFE SCIENCES, IT/TELECOM and INTERNET are positive and broadly significant. This can be explained by the fact that firms in these industries have a higher growth potential, a higher degree of uncertainty and a higher need for the entrepreneur's contribution to the firm.

To seize the idea of the entrepreneur's importance to the firm explicitly, we run several additional regressions (see table 7). In a first step, we include E EXPERT (variant a) and, in a second step, the three different dummy variables concerning the entrepreneur's human capital (variant b): REPEAT ENTREPRENEUR, SCIENCE BACKGROUND and RESEARCH DEGREE. We run each variant for three different specifications. First of all, we include the fixed asset ratio in order to test our hypothesis. Whereas the fixed asset ratio is not significant in the first variant, it is significant at the $10 \%$ level in the second one. This result is not robust to the inclusion of AGE, for example. We then run the

\footnotetext{
${ }^{18}$ Interestingly, the coefficient turns out to be highly significant when coding the negative values as zeros. The same is true for the means which differ at the $5 \%$ significance level. The result should be handled with precaution, however, as these "unclassifiable" observations may be the driving force. Therefore, further research is necessary at this point.
} 
regression with two of our proxy variables (AGE, EARLY STAGE) ${ }^{19}$. It turns out that while our proxy variables continue to be highly significant, neither E EXPERT nor the individual human capital variables are significant.

To conclude, we can say that the regression results are in line with the descriptive statistics. They confirm the first part of hypothesis 1 that states that the higher the uncertainty, the higher the degree of asymmetric information and the more difficult future monitoring, the more probable is staging. Just as in the t-tests, all our proxies are highly significant in each specification of our regressions. Note, however, that our variables are not able to attribute the decision for staging to "pure" asymmetric information aspects only as developmental aspects seem to matter, too. The importance of the entrepreneur's human capital, on the contrary, is partly confirmed by RESEARCH DEGREE in our descriptive statistics, but none of the human capital variables is significant in the regressions. The same is true for the fixed asset ratio. Thus the second part of hypothesis 1 that states that staging should be the more probable, the more important the entrepreneur's human capital and the less tangible the assets is not confirmed by our data. This result as well as the result concerning the asymmetric information aspect should be handled with precaution, however, due to the high amount of missing values as well as the limitations of our indicator variables.

\subsubsection{Discussion}

Apart from staging, there exist further potential contracting elements with a similar impact. Especially debt grants the VC an exit option or can be used by the entrepreneur as a signaling device just as staging. Even though we focus our analysis on the determinants of the decision for staging and not on substitutabilities and complementarities between different instruments, it is important to check that our results are not driven by the underlying relationship between staging and debt.

However, we cannot directly include a debt variable in the above regressions because debt would be an endogenous variable. It is a contractual element just like staging and thus its use is determined simultaneously to staging. In order to cope with this disadvantage and at the same time do justice to possible substitutability effects, we run robustness checks for our previous results by splitting our sample in one part that includes all observations that have a strong debt component and a second part with all observations that do not have a strong debt component. Strong debt component means pure debt, nonstandard debt or convertibles of the subcategories "US style" or "mixes" (see table 2). For these securities, the dummy DEBT COMPONENT takes value one. We find that the determinants for the

\footnotetext{
${ }^{19}$ Note that AI and RAI as well as REVENUES are highly correlated with the human capital variables so that we cannot include them in our regressions.
} 
staging decision are broadly confirmed for each of the two subsamples ${ }^{20}$.

The major differences are the following. As concerns the descriptive statistics, the time and industry effects which we find for the complete sample, seem to arise almost exclusively from the observations with a strong debt component. The same is true for AUDITED BALANCE SHEET. On the other hand, the significant difference of RESEARCH DEGREE can only be confirmed for the observations without a strong debt component. In addition, the fixed asset ratio turns out to be important for the subsample of observations with a strong debt component although it is neither significant in the subsample of observations without a strong debt component nor in the complete sample. This result is also confirmed in the regressions. Whereas all our proxy variables significantly differ in the descriptive statistics, in the regressions, this is not the case anymore: whereas EARLY STAGE continues to be highly significant in both subsamples, AGE looses its significance for the subsample of observations with a strong debt component (the sign continues to be correct). The reverse is true for BREAK EVEN. AI looses its significance in both subsamples but the sign continues to be negative. With respect to the human capital variables, we do not get any robust results in any of the two subsamples. The regression results must, however, be handled with precaution due to the limited number of observations. To sum up, we get evidence that the determinants of staging do not change fundamentally when splitting our sample in two subsamples according to the use of a strong debt component or not.

In addition, it is interesting to compare our results on staging to the results found in the papers based on US data. As mentioned above, Gompers (1995) [11] as well as Kaplan and Strömberg (2003) and (2004) [15], [16] consider staging in their studies. Gompers shows that the younger the firms, the stronger is the staging effect, i.e. fewer capital is released to the venture and funding duration is shorter. This is broadly in line with our findings: staging is more probable for younger firms. Kaplan and Strömberg (2003) [15] find that round duration is longer for repeat entrepreneurs, while Kaplan and Strömberg (2004) [16] show that round duration increases in the degree of external risk, while the amount of funding that is contingent increases with internal risks. Both findings are again broadly in line with our findings: staging is more probable for firms with higher risks.

To conclude this subsection, the results are quite robust and in line with the existing empirical research: we find that the decision for staging is determined by the degree of uncertainty and asymmetric information the investor is confronted with. Throughout all our regressions, the proxy variables AGE, EARLY STAGE, REVENUES and AI are highly significant. The relative degree of asymmetric information is never significant, however. The same is true for the expected investment amount. With respect to our human capital

\footnotetext{
${ }^{20}$ For sake of brevity, we omit the relevant tables here. Of course, they are available upon request from the authors.
} 
variables, we get mixed results. Whereas the descriptive statistics partly point out such an effect, it is not reconfirmed in the regression results. As mentioned above, these last results should be handled with precaution, however, due to the limitations of our proxy variables.

\subsection{How does milestone financing work?}

As mentioned above, the existence of suitable signals is a crucial prerequisite for the use of milestone financing. This is in strong contrast to round financing which does not call for a contingent contract to be feasible. Thus before analyzing the decision between the different staging modes in more detail in the next section, we want to investigate the specifics of milestone financing.

The essential requirement for milestone financing is - as mentioned - the existence of suitable milestones which must be able to describe the expected development of the firm in the future. Therefore, the specific type used should heavily depend on the development stage of the firm. We distinguish four different categories of milestones in our data set: product milestones such as the completion of a prototype or satisfactory product tests, financial milestones such as a minimum sales level or other (firm specific) milestones. One typical example for these other milestones is the hiring of a specific type of manager but this category comprises a broad range of different milestones. Finally, we classify all mixtures of different milestone types as a separate category.

The descriptive statistics for the different kinds of milestones can be found in table 9. These descriptive statistics give us first insights that product and financial milestones seem to be used in successive development stages. We observe that product milestones (in comparison to all other types of milestones) are used more frequently with a higher absolute and relative degree of asymmetric information, for firms which are about to start their development process and for which the entrepreneur's human capital is crucial. On the contrary, product milestones are used less often with firms which already entered the market, which have a finished product, reference customers and reached break-even. By comparison, financial signals are more frequently used with a lower degree of asymmetric information, in firms with reference customers and in which the entrepreneur's human capital is only of marginal importance. These results are also confirmed by our univariate probit regressions which we run with each milestones dummy as independent variable. In table 10, we see that both AI and RAI as well as PRODUCT DEVELOPMENT are significant in the probit regressions for product milestones. This strengthens our result that product milestones are rather used for firms in very early development stages, i.e. for firms for which the product development is the main challenge. By contrast, as concerns the regressions with FINANCIAL MILESTONE as independent variable, we find that AGE, 
AI, and REFERENCE CUSTOMERS are positive and significant whereas PRODUCT DEVELOPMENT is negative significant. This, in turn, underlines our descriptive statistics stating that financial milestones are used with more developed firms as only for these kind of firms financial statements become really meaningful.

The remaining two milestone type categories, namely other, firm-specific milestones and mixes, seem to be used in quite heterogeneous cases. The only variables that are significant in the regressions (see table 11) are the following: for other milestones, the PRODUCT DEVELOPMENT is negative significant. This shows that if the firm is about to start its product development process, other milestones are used less frequently. This result is intuitive as product signals are certainly optimal in this case. The same insights can be derived from our descriptive statistics, too. Interestingly, the mean of the expected investment amount is significantly higher for other milestones relative to all other types of milestones: firms that need more funding to complete their project are more inclined to use firm-specific milestones. As concerns signal mixes, we do not get any robust results neither in the descriptive statistics nor in the univariate probit regressions. Mixes seem to be used in quite heterogeneous cases which we are not able to identify given our data.

It is further interesting to see whether the use of specific milestones differs between mixes and pure milestone financing. In table 8 , we observe that product milestones are used significantly more with mixes than with pure milestone financing; that there does not exist a significant difference in the use of financial and other milestones; and that milestone mixes are used more with pure milestone financing than with mixes (though the difference is only significant at the $11 \%$ level). In subsection 2.2 , we noted that adequate milestones must be available for the whole development process in order to be able to implement pure milestone financing. As product milestones cover only the first part of the development process, it is clear that they should be used more often with mixes than with pure milestone financing. As financial and other milestones are used for more advanced firms, they can, in principle, describe the remaining development process. This implies that there should not exist a significant difference in the use of financial and other milestones between the two forms. The difference in the use of milestone mixes may be explained by two facts: one the one hand, if suitable milestone mixes can be defined, such a mix is able to cover the whole development process; on the other hand, it is quite costly to define a mix of different milestones. Thus it is clear that milestone mixes are indeed observed more often with pure milestone financing than with mixes.

To conclude, our data gives us first insights with respect to the use of different milestone types. We find that product and financial milestones are used in successive development stages and that the availability of milestones seems to be important when choosing one form of staging or another. 


\subsection{The determinants of the different forms of staging}

In this last section, we analyze the determinants of the choice of one of the different forms of staging by testing hypothesis 2 . Once we look at the data, a major problem arises: in contrast to the theoretical discussion that focuses on the differences between round and milestone financing, we additionally observe mixes of these two forms. Therefore, in a first step, we attempt to explain the appearance of mixes and reinterpret hypothesis 2 from this new perspective. Moreover, we have to discuss the instrumentalization of this hypothesis. In a second step, we present descriptive results before running multinomial probit models in order to identify the determinants of the use of the different staging forms. The section concludes with a summary of our results.

\subsubsection{Instrumentalization of the hypothesis}

Hypothesis 2 states that given feasibility of both forms of staging, round financing relative to milestone financing should be the more probable, the better the entrepreneur's outside financing option, the less pronounced the heterogeneity of beliefs between the contracting parties and the higher the total investment amount. In order to test this hypothesis, adequate proxies for the entrepreneur's outside financing option and the heterogeneity of beliefs between the contracting parties as well as the total investment amount are necessary. Moreover, we have to instrumentalize the feasibility aspect what will allow us to explain the appearance of mixes.

As concerns feasibility, one has to distinguish the feasibility of milestone financing and the feasibility of round financing. As concerns the feasibility of milestone financing, the crucial prerequisite is the availability of adequate milestones. This implies - as suggested by our results about the characteristics of milestone financing - that for very early stage firms, pure milestone financing may not be feasible because adequate milestones can only be defined for the near future and not for the whole development process. In this case, round financing is always necessary to implement staging. Then mixes between milestone and round financing may act as a second-best choice to overcome the negative effects of potential hold-up by the VC. This is due to the fact that with mixes in comparison to pure rounds, a new financing round only becomes necessary later on once more reliable information exists. Still we have to bear in mind that ex post flexibility is reduced when using mixes. If pure milestone financing is feasible, all three staging modes can be chosen and the decision depends on the trade-off between the negative incentive effect and ex post flexibility.

With respect to the feasibility of pure round financing, we mentioned in subsection 2.2 that because of prohibitively high contracting costs, each round may have to cover a minimum length. If this is the case, with pure round financing, the effect of staging 
is less pronounced than with pure milestone financing: negative NPV projects may be abandoned only relatively late, for example. Consequently, a strong staging effect can be implemented solely by pure milestone financing or mixes between rounds and milestones. If we assume that for firms with a high degree of asymmetric information and uncertainty, a strong staging effect is more desirable, either pure milestone or mixes should be used with these firms. In this case, mixes may act as a second-best alternative to reduce the loss of ex post flexibility.

With these two problems in mind, we can concretize hypothesis 2. In addition, we conjecture that heterogeneity of beliefs between the contracting parties is only relevant with early stage firms. If the feasibility of milestone financing is the limiting factor, we get the following modified hypothesis:

\section{Hypothesis 2a:}

- Pure milestone financing relative to both pure round financing and mixes should be observed more frequently with more advanced firms for which adequate milestones can be defined for the whole remaining development process.

- Pure milestone financing relative to pure round financing and mixes should be observed more frequently for firms with a worse outside financing option and with a lower total investment amount.

- Mixes relative to pure round financing should be observed more frequently for firms with a worse outside financing option and with a more pronounced heterogeneity of beliefs between the contracting parties.

If the feasibility of round financing is the limiting factor, we get the following competing modified hypothesis:

\section{Hypothesis 2b:}

- Pure round financing relative to both mixes and pure milestone financing should be observed more frequently with more advanced firms for which a strong staging effect is no longer necessary.

- Pure round financing relative to pure milestone financing and mixes should be observed more frequently for firms with a better outside financing option and with a higher total investment amount.

- Mixes relative to pure milestone financing should be observed more frequently for firms with a better outside financing option, with a less pronounced heterogeneity of beliefs between the contracting parties and with a higher total investment amount.

In order to test these modified statements about the determinants of the different forms of staging, we need suitable proxy variables for the entrepreneur's outside financing option, the degree of heterogeneity of beliefs as well as the total investment amount. 
With respect to the entrepreneur's outside financing option, we conjecture that both the information available when conditions are renegotiated as well as previous contacts with other investors besides the VC may play a crucial role. If the VC, as an inside investor, refuses to continue to fund a project, this is a negative signal for outside investors. Thus the entrepreneur has to convince possible investors of the profitability of his project. Therefore, he needs credible, hard information. This means that the degree of asymmetric information must be relatively low. In addition, in an advanced development stage, the firm has already established a relatively long track record. This, of course, may also help to ameliorate the entrepreneur's outside financing option. On the other hand, if the project was or is financed by financial intermediaries other than the (lead) VC (banks, syndicating VCs, angels), the entrepreneur's outside financing option is better as he may also resort to these (former) inside investors for new funding.

With respect to the heterogeneity of beliefs, we conjecture that it should be the more pronounced the higher the degree of asymmetric information and uncertainty because each contracting party holds its own expectations about the future. Naturally, entrepreneurs tend to be more optimistic than VCs. However, as soon as hard facts exist about the profitability of the project, beliefs should become less subjective and therefore more homogeneous.

In order to reflect the mentioned ideas, we use different indicator variables for the development stage of the firm (PRODUCT DEVELOPMENT, MARKET ENTRY), the degree of asymmetric information (AI, its single components and RAI to reduce the developmental aspect), the tangibility of assets (FAR) and the existence of further investors (OUTSIDE FINANCE). Moreover, we use the expected balance sheet EBS as a proxy for the total investment size. Finally, we use E EXPERT as a proxy variable for the importance of the entrepreneur's human capital because we expect the negative incentive effect of potential hold-up by the VC to be the more harmful the more important the entrepreneur's contribution.

\subsubsection{Descriptive results}

We start by comparing the means of firms that use pure milestones to those that use pure round financing. The summary statistics are given in table 12 . We observe that firm characteristics do not play any significant role. This may be explained by the fact that the mentioned feasibility problems are both relevant and that therefore, there do not exist any significant differences. But we observe that the expected funding needs (EBS) are significantly higher with milestones. This contradicts the argument of Cuny and Talmor (2004) [9] that milestone financing should be used less often with higher investment amounts because it reduces the entrepreneur's incentives. The result should 
be handled with precaution because of the limitations of our variable ${ }^{21}$. However, the result can also be interpreted from a different angle: when the entrepreneur's financing needs are relatively large, he crucially depends on the subsequent injection of funds. This implies that it should be more difficult to find an outside investor due to the relatively high amount of funding necessary, i.e. to his relatively bad outside financing option. This argument is further underlined by the significant difference in the means of OUTSIDE FINANCE. In addition, there are both VC and time effects.

The decision between pure milestone financing and a mix of milestone and round financing, on the other hand, is determined by firm characteristics. If the degree of asymmetric information decreases, pure milestone financing becomes more probable than mixes. The same is true for RAI. In addition, the means of different variables that proxy for the development stage of the firm differ significantly, indicating that milestone financing is rather used with more developed firms. See, for example, PRODUCT DEVELOPMENT, MARKET ENTRY, FINISHED PRODUCT as well as REVENUES. This supports hypothesis $2 \mathrm{a}$ and more concretely the assumption that the foreseeability aspect is crucial: pure milestone financing can only be implemented for more developed firms for which adequate milestones can be defined. At the same time, this contradicts hypothesis $2 \mathrm{~b}$ which predicts that both forms of staging should be equally likely for early stage firms. On the other hand, we find evidence for the impact of the hold-up problem on the choice of one of these two forms of staging. First, the mean of the expected funding needs (EBS) is significantly higher for pure milestone financing. This underlines again that the outside option of the entrepreneur is the worse, the higher the funding needs and thus, milestone financing is more advantageous. Second, the mean of OUTSIDE FINANCE is significantly lower for firms that use milestone financing: mixes are used more frequently when other financial intermediaries than the (lead) VC are or were involved in the firm. Then the outside financing option of the entrepreneur is better and so the negative impact of round financing decreases. Finally, there are VC type effects.

In a last step, we consider the decision between pure round financing and mixes. We see that the mean of PRODUCT DEVELOPMENT is significantly higher for mixes than for pure round financing. The same is true for E-EXPERT as well as its component RESEARCH DEGREE. Consequently, a firm in an earlier development stage, which is confronted with a higher degree of uncertainty and for which the entrepreneur's human capital is crucial, tends to use more mixes than pure round financing ${ }^{22}$. This result can be explained by both hypotheses: given the foreseeability problem, mixes are the best way to avoid hold-up by the $\mathrm{VC}$ when pure milestone financing is impossible because adequate milestones cannot be defined for the whole development process ex ante. The hold-up problem is expected

\footnotetext{
${ }^{21}$ The variable where we coded the negative values as zeros also turned out to be insignificant.

${ }^{22}$ This result is further emphasized by the dummy REFERENCE CUSTOMERS.
} 
to be the more pronounced, the less developed the firm in the moment of investment: the less developed the firm, the smaller the probability that hard facts about its success are available when new funding becomes necessary. Thus hypothesis $2 \mathrm{a}$ is confirmed. On the other hand, given the contracting cost problem, round financing is not desirable for rather early stage firms and in this case, mixes are the second-best choice. Thus hypothesis $2 \mathrm{~b}$ is also confirmed. Finally, VC effects and time effects can be observed.

To conclude, we find that although hypothesis $2 \mathrm{a}$ is broadly confirmed by our descriptive statistics, hypothesis $2 \mathrm{~b}$ cannot be completely rejected: both the definition of adequate milestones for the whole development process as well as the minimum duration of pure round financing seem to be limiting factors. In addition, the influence of the hold-up potential by the VC is crucial in the choice of one specific form of staging.

\subsubsection{Regression results}

As pointed out above, we are interested in identifying the determinants of the different forms of staging given that staging is to be implemented. The contracting parties maximize the utility they derive from a specific form of staging by taking into account the advantages and disadvantages of each form. In order to reflect this unobserved utility maximization, we use a discrete choice model. As we want to test two competing hypotheses which imply different logical orders for the three staging modes, we refrain from implementing such an order empirically. Therefore, the appropriate model in our situation is an unordered multinomial logit or probit model. In fact, we will run multinominal probit regressions with varying base categories to avoid the IIA assumption implicit in the multinomial logit model. The results are given in tables 13 and 14 .

With respect to the decision between pure milestone financing and pure round financing, we get the following results: pure milestone financing is used significantly more often for firms which have already entered the market and that are confronted with a lower degree of asymmetric information (measured by both AI and RAI). This means that milestones in comparison to pure round financing are rather used for more advanced firms for which the project's development is predictable and thus adequate milestones can be implemented. This result clearly contradicts hypothesis $2 \mathrm{~b}$ and confirms hypothesis $2 \mathrm{a}$ : the feasibility of milestone financing seems to be the crucial limitation when choosing between the different forms of staging. In addition, OUTSIDE FINANCE is negative and highly significant in all specifications. This indicates that milestone financing is used when the entrepreneur's outside option is relatively low as he cannot resort to former investors or additional syndicating partners when the (lead) VC denies further funding. The expected investment amount (EBS) does not turn out to be significant in our regressions anymore when explicitly controlling for the outside financing option. Thus besides the feasibility 
aspect the impact of potential hold-up by the $\mathrm{VC}$ is the crucial determinant. Finally, the time and $\mathrm{VC}$ effects which we observe in the descriptive statistics are confirmed: public VCs use significantly more pure milestone financing and in period 1, significantly less pure milestone financing is used whereas in period 3 significantly more pure milestone financing is used. This indicates a steady decline in the use of pure round financing.

With respect to the use of mixes relative to pure round financing, we find that mixes are more often used for very early stage firms, i.e. for firms which are on the verge of starting their product development process. This underlines hypothesis $2 \mathrm{a}$ that mixes are implemented to avoid hold-up when pure milestone financing is not feasible, i.e. for very early stage firms where the project's development path is unpredictable and the probability that hard facts will be available when new funding becomes necessary is very low. In addition, we again observe time and VC effects: mixes are used significantly less in period 1 and public and independent VCs are more inclined to use mixes in comparison to pure rounds. The results for independent VCs are not robust, however.

Finally, as concerns the use of mixes relative to pure milestone financing, we observe that mixes are more often used when the product development is about to start, the firm has not already entered the market, the degree of asymmetric information is relatively high and the entrepreneur's human capital is crucial. While this seems counterintuitive at a first view, it underlines hypothesis 2a, i.e. the foreseeability aspect, namely that milestone financing is not implementable for very early stage firms. At the same time, it contradicts hypothesis $2 \mathrm{~b}$ which predicts that both forms are to be used in the same development stages. Moreover, OUTSIDE FINANCE is negative. Although the coefficients are not significant in all our specification, the sign is always correct, indicating that milestone financing is rather used when the hold-up potential is pronounced, i.e. when the entrepreneur cannot resort to other (known) financiers. This means that both foreseeability and renegotiation aspects are important when choosing milestone financing or mixes. Finally, we find that the $\mathrm{VC}$ and time effects are not robust in our regressions but there is a tendency that independent VCs use significantly less pure milestones and that in period 3 , significantly more pure milestone financing was used.

Thus we can state that the descriptive results are in line with the regressions and thus with hypothesis 2a. All in all, this means that there exist two different determinants: first of all, foreseeability decides whether pure milestone financing is feasible; second, the intensity of the hold-up problem determines the choice between the available forms of staging. Contracting cost arguments do not seem to play an important role for the feasibility of round financing. 


\subsubsection{Summary}

To sum up, the choice between the different forms of staging is driven by the anticipation of the impact of renegotiation possibilities: we find that contracts are the more complete, the more pronounced the negative expected incentive effect for the entrepreneur caused by the VC's hold-up. At the same time, the foreseeability of the project's development severely restricts contract completeness by rendering milestone financing impossible.

Complete contingent contracts are only feasible if foreseeability is given. This implies that pure milestone financing should be more probable for more advanced firms what is broadly confirmed by our data. If foreseeability is given, milestone financing should be used more often than mixes if the negative incentive effect is pronounced. The same should be true for the comparison between pure milestone financing and round financing. Again, this is just what we find in our data: if the entrepreneur has a good outside financing option due to contacts to former investors or other investors in the syndicate, the hold-up potential and therefore, the negative incentive effects are less pronounced ${ }^{23}$. Consequently, milestone financing is used less frequently than mixes and than pure rounds.

If complete contingent contracts cannot be implemented because foreseeability is not given, the choice to be made is only between mixes and pure round financing. In this case, mixes are the most complete contracts available. Thus mixes should be used more often than pure rounds when the impact of potential renegotiation is pronounced. Indeed, the data shows that mixes are used with less developed firms for which hard information is not expected to be available in the near future and consequently, outside funding will be difficult to obtain.

\section{Conclusion}

The aim of this paper is to analyze the determinants of staging per se as well as its different modes. Thereby, we do not only focus on the VC specific literature but also on the literature on renegotiation to deduce relevant hypotheses which we test against our data.

We find that the decision for staging is driven by the extent of asymmetric information and uncertainty in the firm. It is important to keep in mind that we proxy for asymmetric

\footnotetext{
${ }^{23}$ In order to test the robustness of OUTSIDE FINANCE, we ignore the existence of syndicating VCs for a moment. We conjecture, however, that the possibility to resort to syndicating partners is crucial for the entrepreneur when the (lead) VC denies further funding. This is especially important as syndicating partners have a further informational advantage in comparison to former investors which financed the venture before the initial VC investment. It turns out that, as expected, this alternative specification hardly yields any significant results anymore. However, there is no contradiction with respect to the previous mentioned results either. For sake of brevity, we omit the relevant tables here. Of course, they are available upon request from the authors.
} 
information by taking a developmental perspective. On the contrary, the tangibility of assets and the entrepreneur's human capital do not matter. With respect to these results, it is important to keep in mind the limitations of our variables. Still, the results are quite robust and in line with earlier studies based on US data.

As regards the characteristics of milestone financing, we present evidence that the type of milestone used depends on the position of the firm in its development process. Very early stage firms tend to use product milestones while developed firms use financial or other milestones. Moreover, product milestones seem to be used more often with mixes between round and milestone financing. Mixes of different types of milestones, on the other hand, seem to be used more often with pure milestone financing.

Finally, we are able to show that for the decision between the different forms of staging the investment amount does not seem to play a significant role. Rather the trade-off between the anticipation of the impact of renegotiation on the entrepreneur's incentives and the desired ex post flexibility is decisive: the more pronounced the negative incentive effect caused by renegotiation, the more complete contracts should be in order to limit hold-up by the VC. However, the degree of contract completeness is restrained by the need for predictability of the project's development path. If this is not the case, pure milestones (and therefore complete contracts) are impossible to define and mixes present a secondbest choice to overcome the negative incentive effect. Both aspects are confirmed by our data. To be more precise, we show that pure milestone financing is used less frequently for very early stage firms for which predictability is less probable. Our data further confirms that the degree of contract completeness depends on the entrepreneur's outside financing option which we measure in two forms: first, we look whether external funding before the investment of the VC has taken place or whether the investment is (or was) made via a syndicate of VCs and second whether hard information is available. 


\section{References}

[1] Philippe Aghion, Mathias Dewatripont, and Patrick Rey. Renegotiation design with unverifiable information. Econometrica, 62:257-282, 1994.

[2] Andreas Bascha and Uwe Walz. Financing practices in the german venture capital industry: An empirical assessment. CFS Working Paper No. 2002/08, 2003.

[3] Jochen Bigus. Staging of venture financing, moral hazard, and patent law. German Working Papers in Law and Economics, 2002(25), 2002.

[4] Laura Bottazzi, Marco Da Rin, and Thomas Hellmann. The changing face of the european venture capital industry: Facts and analysis. Journal of Private Equity, 8, 2004.

[5] German Venture Capital Association (BVK). BVK Statistik 2003. BVK, Berlin, 2003.

[6] German Venture Capital Association (BVK). Jahresbericht 2003. BVK, Berlin, 2003.

[7] Francesca Cornelli and Oved Yosha. Stage financing and the role of convertible securities. Review of Economic Studies, 70:1-32, 2003.

[8] Douglas J. Cumming. Contracts and exits in venture capital finance. Unpublished Working Paper, 2002.

[9] Charles J. Cuny and Eli Talmor. The staging of venture capital financing: Milestone vs. rounds. Unpublished Working Paper, 2004.

[10] Wouter Dessein. Information and control in alliances \& ventures. Forthcoming, Journal of Finance, 2004.

[11] Paul Gompers. Optimal investment, monitoring, and the staging of venture capital. Journal of Finance, 50:1461 - 1489, 1995.

[12] Paul Gompers and Jeff Lerner. The Venture Capital Cycle. MIT Press, Cambridge, Massachussetts, 1999.

[13] J. Luis Guasch, Jean-Jacques Laffont, and Stephane Straub. Renegotiation of concession contracts in latin america. Unpublished Working Paper, 2003.

[14] Thomas Hellmann. Financial Structure and Control in Venture Capital. PhD thesis, Stanford University, 1994. 
[15] Steve Kaplan and Per Strömberg. Financial contracting meets the real world: An empirical analysis of venture capital contracts. The Review of Economic Studies, 70:281-316, 2003.

[16] Steve Kaplan and Per Strömberg. Characteristics, contracts, and actions: Evidence from venture capitalist analyses. Journal of Finance, 59:2177-2210, 2004.

[17] Steven Kaplan, Frederic Martel, and Per Strömberg. How do legal differences and learning affect financial contracts? Unpublished Working Paper, 2003.

[18] Darwin Neher. Staged financing: An agency perspective. Review of Financial Studies, 66:255-274, 1999.

[19] Georg Nöldeke and Klaus M. Schmidt. Option contracts and renegotiation: a solution to the hold-up problem. Rand Journal of Economics, 26:163-179, 1995.

[20] Raghuram Rajan. Insiders and outsiders: The choice between informed and arm'slength debt. Journal of Finance, 47(4):1367-1400, 1992.

[21] Rafael Repullo and Javier Surez. Venture capital finance: A security design approach. Review of Finance, 8:75-108, 2004.

[22] Gil Ricard. Renegotiation and relational contracts. Unpublished Working Paper, 2005.

[23] Susheng Wang and Hailan Zhou. Staged financing in venture capital: Moral hazard and risks. Unpublished Working Paper, 2002. 


\section{Tables}

Table 1: Sample Selection

\begin{tabular}{|l|cccc|}
\hline \hline & -1997 & $1998-2000$ & $2000-2004$ & Total \\
\hline \hline 1 & 51 & 102 & 22 & 175 \\
\hline 10 & 0 & 12 & 4 & 16 \\
\hline 11 & 0 & 8 & 1 & 9 \\
\hline 100 & 4 & 16 & 2 & 22 \\
\hline 1000 & 1 & 33 & 32 & 66 \\
\hline 1001 & 0 & 6 & 3 & 9 \\
\hline 1010 & 0 & 1 & 1 & 2 \\
\hline 1011 & 0 & 1 & 0 & 1 \\
\hline \hline Total & 56 & 179 & 65 & 300 \\
\hline \hline
\end{tabular}

Notes: 1 = Technology Participation Programme (KfW/BMWA + KfW/BMTF - Technologie-Beteiligungsprogramm); 10 = ERP-Innovation Programme (ERP-Innovationsprogramm (Beteiligungsvariante)); 100 = Guarantee Programme (KfWRisikokapitalprogramm - Garantien); 1000 = Fund Programme (KFW-Risikokapitalprogramm - Fondsfinanzierung); and mixes

Table 2: Summary Statistics I: Security Choice

\begin{tabular}{|c|c|c|c|c|c|c|c|c|c|}
\hline Category & \multicolumn{2}{|c|}{ Equity } & \multicolumn{2}{|c|}{ Debt \& Equity } & \multicolumn{3}{|c|}{ Convertibles } & \multicolumn{2}{|l|}{ 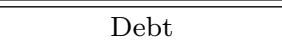 } \\
\hline Description & $\begin{array}{l}\text { Pure } \\
\text { Equity }\end{array}$ & $\begin{array}{l}\text { Equity } \\
+\mathrm{LP}\end{array}$ & $\begin{array}{l}\text { Debt> } \\
\text { Equity }\end{array}$ & $\begin{array}{l}\text { Debt }< \\
\text { Equity }\end{array}$ & US Style & $\begin{array}{l}\text { Convertible } \\
\text { Equity }\end{array}$ & Mixes & $\begin{array}{c}\text { Nonstandard } \\
\text { Debt }\end{array}$ & $\begin{array}{l}\text { Pure } \\
\text { Debt }\end{array}$ \\
\hline Category & 1 & 2 & 3 & 5 & 6 & 7 & 8 & 4 & 9 \\
\hline Upside Cash Flow Rights & $\mathrm{X}$ & $\mathrm{X}$ & $\mathrm{X}$ & $\mathrm{X}$ & $\mathrm{X}$ & $\mathrm{X}$ & $\mathrm{X}$ & $\mathrm{X}$ & - \\
\hline Downside Protection & - & $\mathrm{X}$ & $\mathrm{X}$ & - & $\mathrm{X}$ & $\mathrm{X}$ & $\mathrm{X}$ & $\mathrm{X}$ & $\mathrm{X}$ \\
\hline Change of Control & - & - & $\mathrm{X}$ & $\mathrm{X}$ & $\mathrm{X}$ & - & $\mathrm{X}$ & $\mathrm{X}$ & $\mathrm{X}$ \\
\hline Cash Flow Rights at Exit & $\mathrm{X}$ & $\mathrm{X}$ & $\mathrm{X}$ & $\mathrm{X}$ & $\mathrm{X}$ & $\mathrm{X}$ & $\mathrm{X}$ & - & - \\
\hline Voting Rights & $\mathrm{X}$ & $\mathrm{X}$ & $\mathrm{X}$ & $\mathrm{X}$ & - & $\mathrm{X}$ & $\mathrm{X}$ & - & - \\
\hline & 51 & 85 & 157 & 20 & 11 & 10 & 16 & 11 & 96 \\
\hline Total Percentage & \multicolumn{2}{|c|}{$29 \%$} & \multicolumn{2}{|c|}{$38 \%$} & \multicolumn{3}{|c|}{$8 \%$} & \multicolumn{2}{|l|}{$23 \%$} \\
\hline
\end{tabular}

Notes: We report the VC's security choice which is categorized according to the indicated five characteristics. We were confronted with 7 missing values.

Table 3: Summary Statistics II: Staging Behavior

\begin{tabular}{|l|cc|ccc|}
\hline \hline & No Staging & Staging & Pure Milestones & Pure Rounds & Mixes \\
\hline Complete Sample & $135(0.30)$ & $311(0.70)$ & $53(0.17)$ & $181(0.59)$ & $73(0.24)$ \\
\hline Period 1 & $18(0.28)$ & $46(0.72)$ & $3(0.07)$ & $38(0.86)$ & $3(0.07)$ \\
Period 2 & $86(0.34)$ & $167(0.66)$ & $25(0.16)$ & $93(0.59)$ & $39(0.25)$ \\
Period 3 & $33(0.24)$ & $106(0.76)$ & $25(0.24)$ & $50(0.47)$ & $31(0.29)$ \\
\hline Independent VC & $66(0.31)$ & $215(0.69)$ & $28(0.14)$ & $117(0.57)$ & $60(0.29)$ \\
Public VC & $44(0.45)$ & $54(0.55)$ & $17(0.32)$ & $27(0.51)$ & $9(0.17)$ \\
Other VC Types & $27(0.36)$ & $48(0.64)$ & $7(0.15)$ & $36(0.77)$ & $4(0.09)$ \\
\hline
\end{tabular}

Notes: The first column refers to the number of observations and the second to the percentage. 


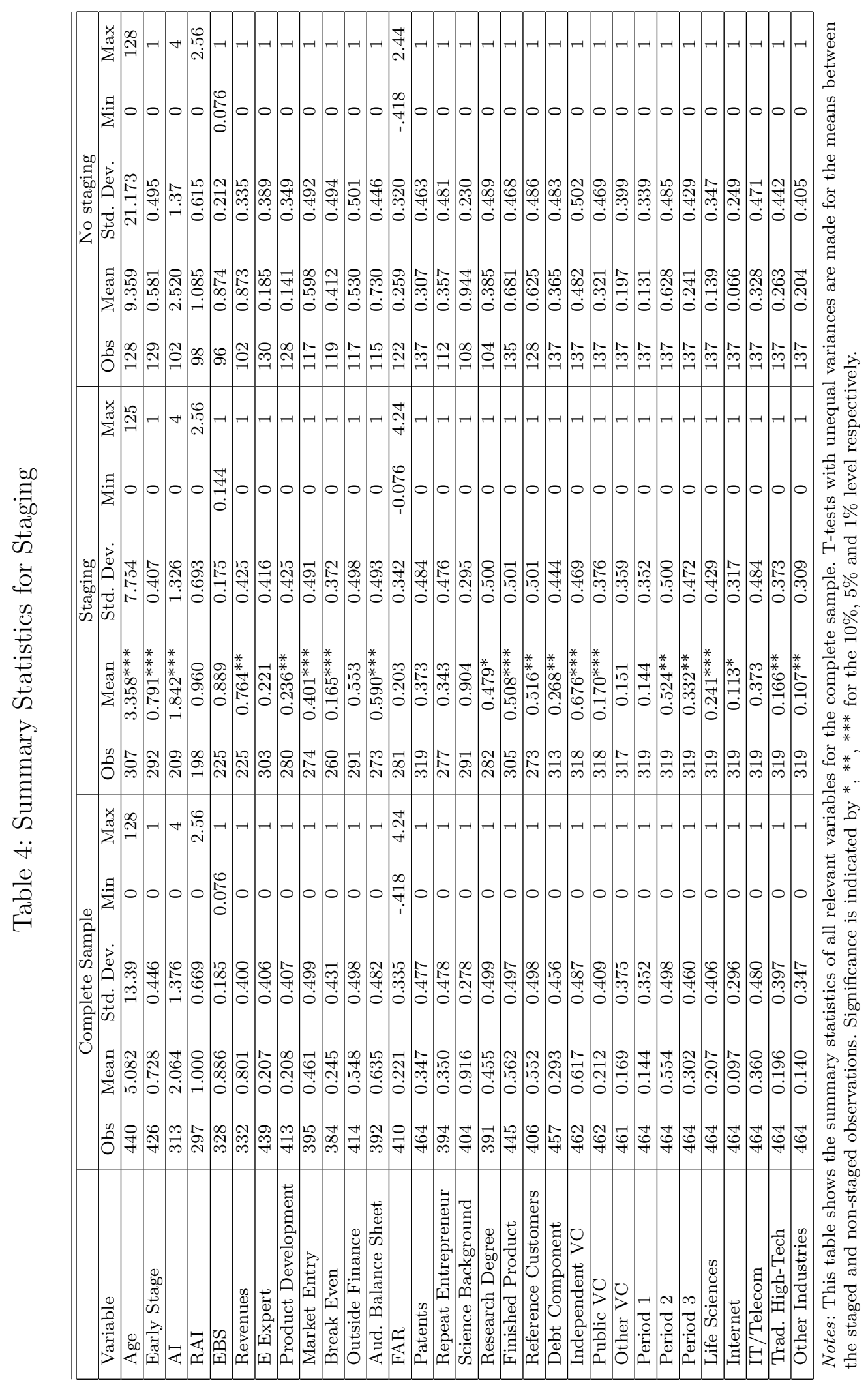




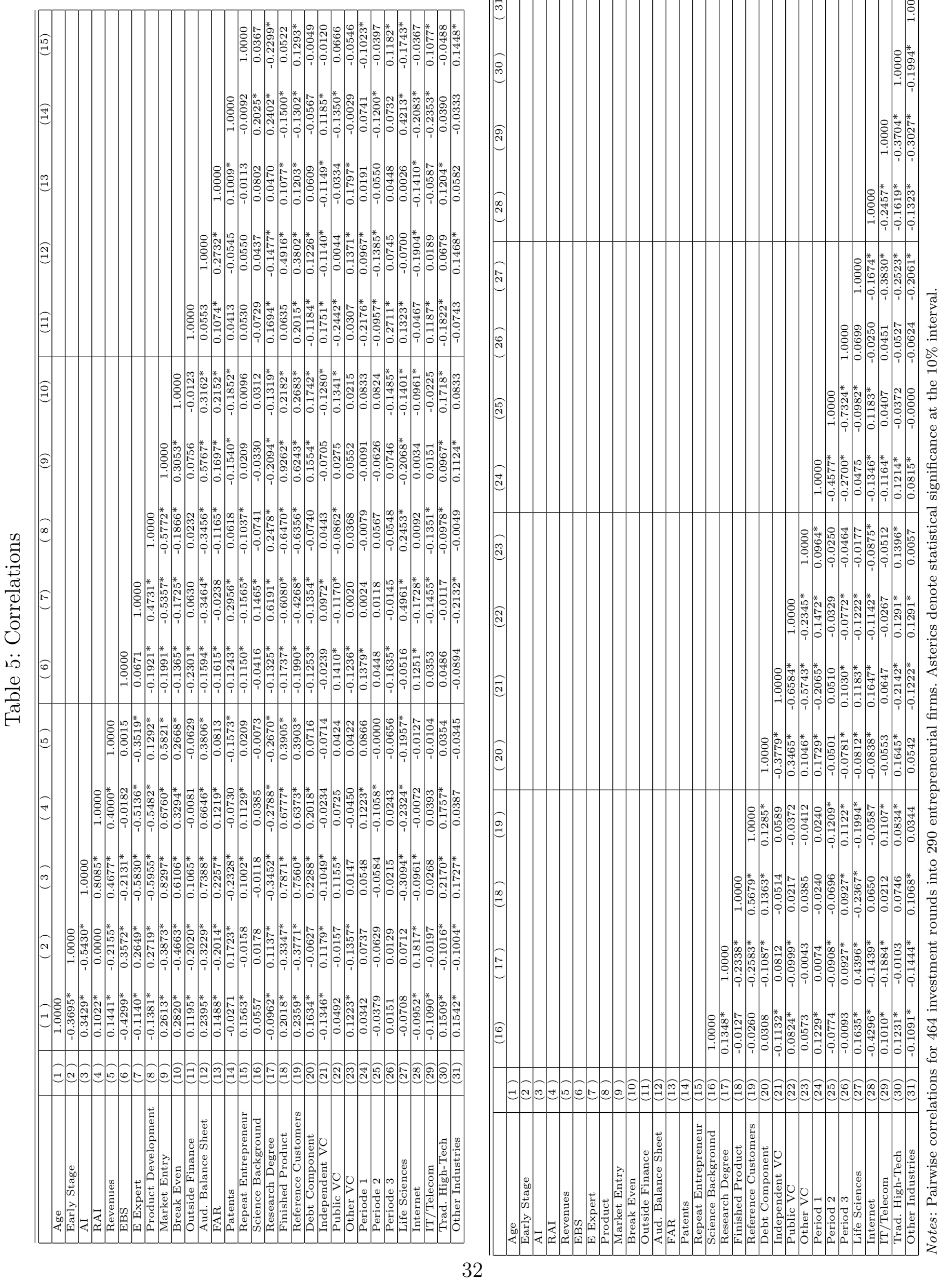




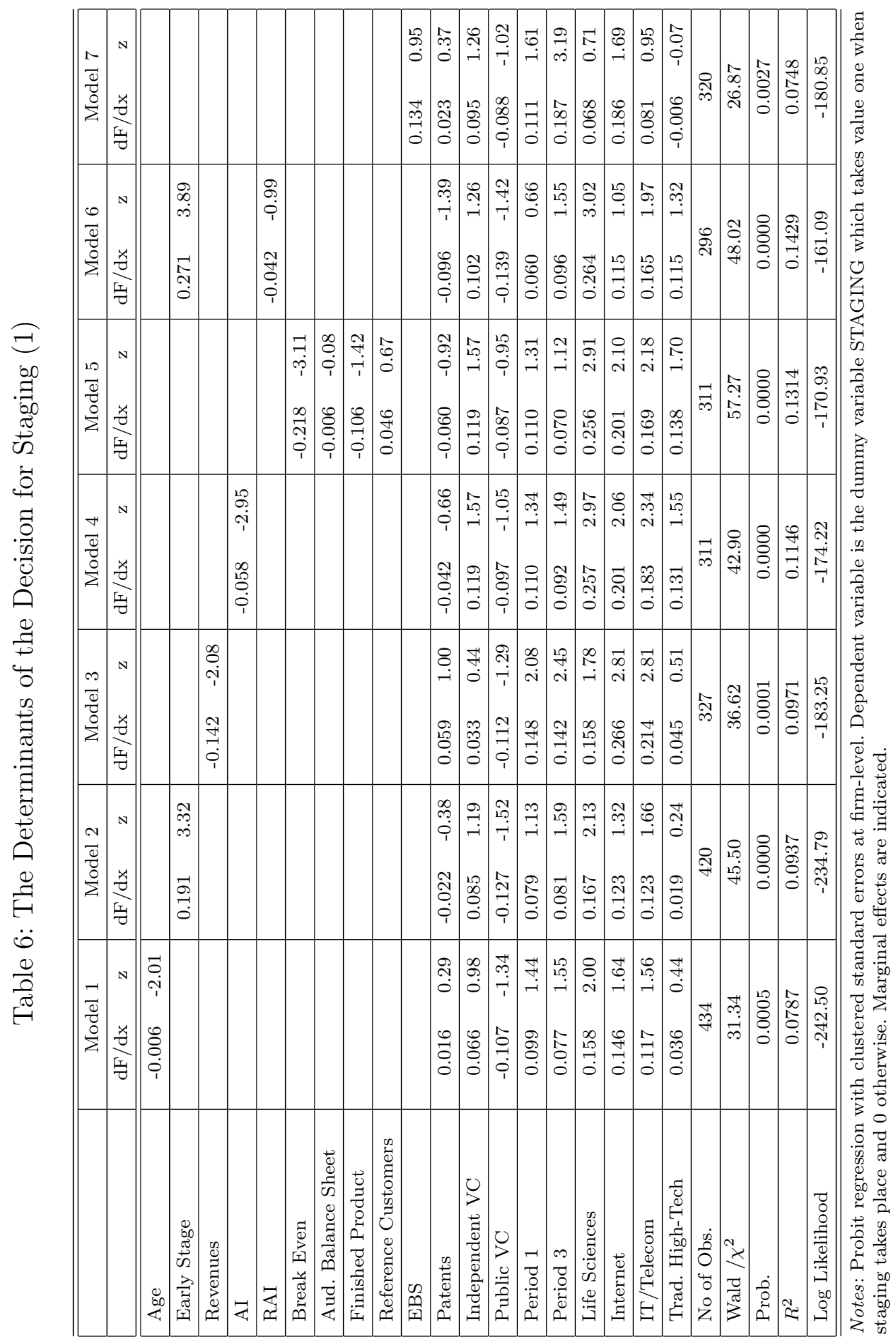


Table 7: The Determinants of the Decision for Staging (2)

\begin{tabular}{|c|c|c|c|c|c|c|c|c|c|c|c|c|}
\hline & \multicolumn{2}{|c|}{ Model 1a } & \multicolumn{2}{|c|}{ Model 1b } & \multicolumn{2}{|c|}{ Model 2a } & \multicolumn{2}{|c|}{ Model 2b } & \multicolumn{2}{|c|}{ Model 3a } & \multicolumn{2}{|c|}{ Model 3b } \\
\hline & $\mathrm{dF} / \mathrm{dx}$ & $\mathrm{z}$ & $\mathrm{dF} / \mathrm{dx}$ & $\mathrm{z}$ & $\mathrm{dF} / \mathrm{dx}$ & $\mathrm{z}$ & $\mathrm{dF} / \mathrm{dx}$ & $\mathrm{z}$ & $\mathrm{dF} / \mathrm{dx}$ & $\mathrm{z}$ & $\mathrm{dF} / \mathrm{dx}$ & $\mathrm{z}$ \\
\hline FAR & -0.073 & -0.86 & -0.148 & -1.65 & & & & & & & & \\
\hline Age & & & & & -0.006 & -2.00 & -0.024 & -3.27 & & & & \\
\hline Early Stage & & & & & & & & & 0.256 & 4.03 & 0.203 & 2.97 \\
\hline E Expert & -0.027 & -0.42 & & & -0.081 & -1.27 & & & -0.114 & -1.59 & & \\
\hline Science Background & & & -0.052 & -0.42 & & & -0.068 & -0.54 & & & -0.092 & -0.83 \\
\hline Repeat Entrepreneur & & & -0.003 & -0.06 & & & 0.017 & 0.32 & & & -0.016 & -0.29 \\
\hline Research Degree & & & 0.049 & 0.85 & & & 0.003 & 0.05 & & & 0.048 & 0.81 \\
\hline Patents & 0.014 & 0.26 & 0.013 & 0.22 & 0.012 & 0.22 & -0.026 & -0.44 & -0.024 & -0.40 & -0.019 & -0.31 \\
\hline Independent VC & 0.083 & 1.17 & 0.086 & 1.13 & 0.073 & 1.06 & 0.114 & 1.49 & 0.078 & 1.08 & 0.081 & 1.04 \\
\hline Public VC & -0.093 & -1.15 & -0.098 & -1.07 & -0.086 & -1.05 & -0.085 & -0.90 & -0.118 & -1.38 & -0.126 & -1.29 \\
\hline Period 1 & 0.115 & 1.69 & 0.091 & 1.24 & 0.108 & 1.53 & 0.080 & 1.05 & 0.087 & 1.20 & 0.089 & 1.19 \\
\hline Period 3 & 0.119 & 2.24 & 0.098 & 1.77 & 0.076 & 1.49 & 0.063 & 1.10 & 0.087 & 1.67 & 0.067 & 1.19 \\
\hline Life Sciences & 0.183 & 2.11 & 0.065 & 0.64 & 0.207 & 2.49 & 0.118 & 1.19 & 0.221 & 2.65 & 0.073 & 0.76 \\
\hline Internet & 0.212 & 2.42 & 0.145 & 1.18 & 0.147 & 1.65 & 0.039 & 0.32 & 0.110 & 1.15 & 0.032 & 0.27 \\
\hline IT/Telecom & 0.140 & 1.86 & 0.033 & 0.37 & 0.118 & 1.56 & 0.044 & 0.48 & 0.116 & 1.52 & 0.037 & 0.43 \\
\hline Trad. High-Tech & 0.050 & 0.61 & -0.029 & -0.28 & 0.059 & 0.72 & 0.021 & 0.21 & 0.040 & 0.49 & -0.045 & -0.46 \\
\hline No of Obs. & \multicolumn{2}{|c|}{383} & \multicolumn{2}{|c|}{298} & \multicolumn{2}{|c|}{411} & \multicolumn{2}{|c|}{322} & \multicolumn{2}{|c|}{400} & \multicolumn{2}{|c|}{311} \\
\hline Wald $/ \chi^{2}$ & \multicolumn{2}{|c|}{33.99} & \multicolumn{2}{|c|}{22.23} & \multicolumn{2}{|c|}{31.90} & \multicolumn{2}{|c|}{25.05} & \multicolumn{2}{|c|}{48.18} & \multicolumn{2}{|c|}{28.42} \\
\hline Prob. & \multicolumn{2}{|c|}{0.0004} & \multicolumn{2}{|c|}{0.0519} & \multicolumn{2}{|c|}{0.0008} & \multicolumn{2}{|c|}{0.0227} & \multicolumn{2}{|c|}{0.0000} & \multicolumn{2}{|c|}{0.0079} \\
\hline$R^{2}$ & \multicolumn{2}{|c|}{0.0755} & \multicolumn{2}{|c|}{0.0635} & \multicolumn{2}{|c|}{0.0838} & \multicolumn{2}{|c|}{0.0851} & \multicolumn{2}{|c|}{0.1084} & \multicolumn{2}{|c|}{0.0823} \\
\hline Log Likelihood & \multicolumn{2}{|c|}{-216.37} & -16 & & -228 & & -16 & & -221 & & -16 & \\
\hline
\end{tabular}

Notes: Probit regression with clustered standard errors at firm-level. Dependent variable is the dummy variable STAGING which takes value one when staging takes place and 0 otherwise. Marginal effects are indicated.

Table 8: The Use of the Different Milestone Types with Pure Milestones and Mixes

\begin{tabular}{|l|ccc|ccc|c|}
\hline \hline & \multicolumn{3}{|c|}{ Pure Milestones } & \multicolumn{3}{c|}{ Mixes } & \\
\hline & Mean & Std. dev. & $\mathrm{N}$ & Mean & Std. dev. & $\mathrm{N}$ & $\operatorname{Pr}(|T|>|t|)$ \\
\hline Product Milestone & 0.208 & 0.409 & 53 & 0.342 & 0.478 & 73 & 0.0915 \\
\hline Financial Milestone & 0.113 & 0.320 & 53 & 0.123 & 0.331 & 73 & 0.8637 \\
\hline Other Milestone & 0.208 & 0.409 & 53 & 0.205 & 0.407 & 73 & 0.9777 \\
\hline Milestone Mix & 0.472 & 0.504 & 53 & 0.329 & 0.473 & 73 & 0.1098 \\
\hline
\end{tabular}

Notes: This table shows the summary statistics of the different milestone types for the use with pure milestone financing and mixes respectively. 


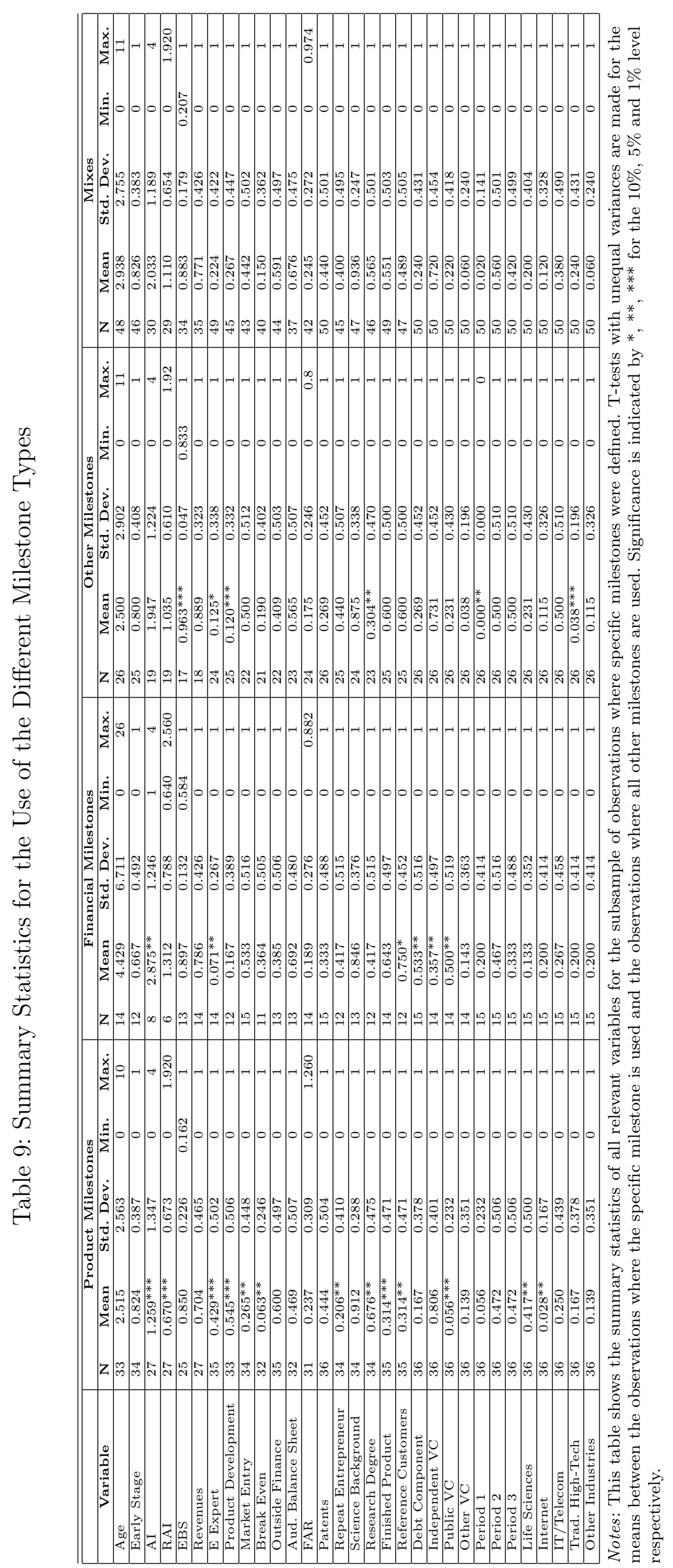


Table 10: The Determinants of a Specific Milestone Category (1)

\begin{tabular}{|c|c|c|c|c|c|c|c|c|c|c|}
\hline \multicolumn{11}{|c|}{ The determinants of product milestones } \\
\hline & \multicolumn{2}{|c|}{ Model 1} & \multicolumn{2}{|c|}{ Model 4} & \multicolumn{2}{|c|}{ Model 2} & \multicolumn{2}{|c|}{ Model 3} & \multicolumn{2}{|c|}{ Model 5} \\
\hline & $\mathrm{dF} / \mathrm{dx}$ & $\mathrm{z}$ & $\mathrm{dF} / \mathrm{dx}$ & $\mathrm{z}$ & $\mathrm{dF} / \mathrm{dx}$ & $\mathrm{z}$ & $\mathrm{dF} / \mathrm{dx}$ & $\mathrm{z}$ & $\mathrm{dF} / \mathrm{dx}$ & $\mathrm{z}$ \\
\hline Age & -0.025 & -1.45 & & & & & & & & \\
\hline Early Stage & & & 0.094 & 0.72 & & & & & & \\
\hline RAI & & & -0.222 & -2.33 & & & & & & \\
\hline AI & & & & & -0.117 & -2.75 & & & & \\
\hline Break Even & & & & & & & -0.051 & -0.29 & & \\
\hline Aud. Balance Sheet & & & & & & & -0.090 & -0.78 & & \\
\hline Finished Product & & & & & & & -0.185 & -1.47 & & \\
\hline Reference Customers & & & & & & & -0.096 & -0.76 & & \\
\hline Product Development & & & & & & & & & 0.269 & 2.78 \\
\hline Patents & -0.043 & -0.49 & 0.066 & 0.54 & 0.046 & 0.39 & 0.039 & 0.32 & -0.027 & -0.29 \\
\hline Independent VC & -0.009 & -0.05 & -0.160 & -0.90 & -0.097 & -0.59 & -0.090 & -0.55 & -0.025 & -0.19 \\
\hline Public VC & -0.239 & -1.51 & -0.323 & -2.01 & -0.292 & -1.87 & -0.288 & -1.83 & -0.209 & -1.41 \\
\hline Period 1 & 0.224 & 1.06 & 0.380 & 1.74 & 0.321 & 1.55 & 0.294 & 1.35 & 0.129 & 0.71 \\
\hline Period 3 & 0.027 & 0.31 & 0.117 & 1.09 & 0.124 & 1.17 & 0.121 & 1.13 & 0.074 & 0.79 \\
\hline Growth Industries & & & 0.039 & 0.31 & 0.033 & 0.27 & 0.024 & 0.20 & & \\
\hline Life Sciences & 0.094 & 0.71 & & & & & & & 0.083 & 0.67 \\
\hline Internet & -0.241 & -2.02 & & & & & & & -0.243 & -1.97 \\
\hline IT/Telecom & -0.161 & -1.44 & & & & & & & -0.127 & -1.08 \\
\hline Trad. High-Tech & -0.125 & -1.14 & & & & & & & -0.066 & -0.56 \\
\hline No of Obs. & \multicolumn{2}{|c|}{120} & \multicolumn{2}{|c|}{81} & \multicolumn{2}{|c|}{84} & \multicolumn{2}{|c|}{84} & \multicolumn{2}{|c|}{115} \\
\hline Wald $/ \chi^{2}$ & \multicolumn{2}{|c|}{20.40} & \multicolumn{2}{|c|}{17.54} & \multicolumn{2}{|c|}{15.68} & \multicolumn{2}{|c|}{16.92} & \multicolumn{2}{|c|}{24.90} \\
\hline Prob. & \multicolumn{2}{|c|}{0.0257} & 0.0 & & 0.0 & & 0.0 & & 0.0 & \\
\hline$R^{2}$ & & & 0.1 & & 0.1 & & 0.1 & & 0.1 & \\
\hline Log Likelihood & -61 & & -43 & & -45 & & -45 & & -56 & \\
\hline & & The d & erminan & of fina & cial mile & ones & & & & \\
\hline & Mo & & Mo & & Mo & & Mo & 3 & Mor & 15 \\
\hline & $\mathrm{dF} / \mathrm{dx}$ & $\mathrm{z}$ & $\mathrm{dF} / \mathrm{dx}$ & $\mathrm{z}$ & $\mathrm{dF} / \mathrm{dx}$ & $\mathrm{z}$ & $\mathrm{dF} / \mathrm{dx}$ & $\mathrm{z}$ & $\mathrm{dF} / \mathrm{dx}$ & $\mathrm{z}$ \\
\hline Age & 0.009 & 1.91 & & & & & & & & \\
\hline Early Stage & & & -0.116 & -1.44 & & & & & & \\
\hline RAI & & & 0.034 & 1.07 & & & & & & \\
\hline AI & & & & & 0.042 & 2.23 & & & & \\
\hline Break Even & & & & & & & 0.018 & 0.37 & & \\
\hline Aud. Balance Sheet & & & & & & & 0.052 & 1.28 & & \\
\hline Finished Product & & & & & & & -0.047 & -1.12 & & \\
\hline Reference Customers & & & & & & & 0.132 & 2.91 & & \\
\hline Product Development & & & & & & & & & -0.061 & -1.65 \\
\hline Patents & 0.053 & 1.00 & 0.049 & 1.22 & 0.071 & 1.75 & 0.052 & 1.63 & 0.057 & 1.15 \\
\hline Independent VC & -0.185 & -1.72 & -0.123 & -1.42 & -0.127 & -1.31 & 0.111 & -1.40 & -0.165 & -1.94 \\
\hline Public VC & -0.013 & -0.15 & -0.009 & -0.15 & -0.007 & -0.09 & 0.001 & 0.02 & -0.014 & -0.19 \\
\hline Period 1 & 0.304 & 1.93 & 0.149 & 1.26 & 0.119 & 1.23 & 0.159 & 1.83 & 0.292 & 1.81 \\
\hline Period 3 & -0.002 & -0.04 & 0.002 & 0.05 & -0.024 & -0.50 & -0.017 & -0.47 & -0.005 & -0.10 \\
\hline Growth Industries & & & -0.053 & -1.07 & -0.047 & -0.90 & 0.043 & -1.01 & & \\
\hline Life Sciences & -0.081 & -1.14 & & & & & & & -0.080 & -1.12 \\
\hline Internet & 0.075 & 0.67 & & & & & & & 0.023 & 0.25 \\
\hline IT/Telecom & -0.030 & -0.46 & & & & & & & -0.067 & -1.02 \\
\hline Trad. High-Tech & -0.040 & -0.57 & & & & & & & -0.043 & -0.59 \\
\hline No of Obs. & & & & & & & & & & \\
\hline Wald $/ \chi^{2}$ & & & & & & & & & & \\
\hline Prob. & & & 0.4 & & 0.0 & & 0.0 & & 0.0 & \\
\hline$R^{2}$ & 0.1 & & 0.1 & & 0.2 & & 0.2 & & 0.1 & \\
\hline Log Likelihood & -33 & & -17 & & -20 & & -18 & & -32 & \\
\hline
\end{tabular}

Notes: Probit regression with clustered standard errors at firm-level. Dependent variable is the dummy variable PRODUCT (FINANCIAL) MILESTONE which takes value one when a financial (product) milestone is used with milestone financing and 0 otherwise. Marginal effects are indicated. 
Table 11: The Determinants of a Specific Milestone Category (2)

\begin{tabular}{|c|c|c|c|c|c|c|c|c|c|c|}
\hline \multicolumn{11}{|c|}{ The determinants of "other" milestones } \\
\hline & \multicolumn{2}{|c|}{ Model 1} & \multicolumn{2}{|c|}{ Model 2} & \multicolumn{2}{|c|}{ Model 3} & \multicolumn{2}{|c|}{ Model 4} & \multicolumn{2}{|c|}{ Model 5} \\
\hline & $\mathrm{dF} / \mathrm{dx}$ & $\mathrm{z}$ & $\mathrm{dF} / \mathrm{dx}$ & $\mathrm{z}$ & $\mathrm{dF} / \mathrm{dx}$ & $\mathrm{z}$ & $\mathrm{dF} / \mathrm{dx}$ & $\mathrm{z}$ & $\mathrm{dF} / \mathrm{dx}$ & $\mathrm{z}$ \\
\hline Age & -0.009 & -0.82 & & & & & & & & \\
\hline Early Stage & & & 0.004 & 0.04 & & & & & & \\
\hline RAI & & & 0.036 & 0.54 & & & & & & \\
\hline AI & & & & & 0.004 & 0.12 & & & & \\
\hline Break Even & & & & & & & 0.007 & 0.05 & & \\
\hline Aud. Balance Sheet & & & & & & & -0.039 & -0.33 & & \\
\hline Finished Product & & & & & & & -0.001 & -0.01 & & \\
\hline Reference Customers & & & & & & & 0.043 & 0.42 & & \\
\hline Product Development & & & & & & & & & -0.159 & -1.94 \\
\hline Patents & -0.100 & -1.19 & -0.175 & -1.78 & -0.179 & -1.95 & -0.179 & -1.98 & -0.085 & -1.04 \\
\hline Independent $\mathrm{VC}$ & 0.094 & 0.59 & 0.081 & 0.45 & 0.120 & 0.71 & 0.112 & 0.66 & 0.131 & 0.90 \\
\hline Public VC & 0.118 & 0.59 & 0.236 & 1.02 & 0.280 & 1.21 & 0.261 & 1.13 & 0.135 & 0.67 \\
\hline Period 3 & 0.095 & 1.25 & 0.036 & 0.38 & 0.045 & 0.49 & 0.042 & 0.46 & 0.060 & 0.81 \\
\hline Growth Industries & & & 0.053 & 0.52 & 0.048 & 0.47 & 0.041 & 0.41 & & \\
\hline Life Sciences & -0.029 & -0.22 & & & & & & & -0.036 & -0.27 \\
\hline Internet & -0.046 & -0.30 & & & & & & & -0.044 & -0.28 \\
\hline IT/Telecom & 0.026 & 0.20 & & & & & & & -0.002 & -0.01 \\
\hline Trad. High-Tech & -0.191 & -1.56 & & & & & & & -0.190 & -1.63 \\
\hline No of Obs. & \multicolumn{2}{|c|}{120} & \multicolumn{2}{|c|}{81} & \multicolumn{2}{|c|}{84} & \multicolumn{2}{|c|}{84} & \multicolumn{2}{|c|}{115} \\
\hline Wald $/ \chi^{2}$ & \multicolumn{2}{|c|}{8.13} & \multicolumn{2}{|c|}{6.50} & \multicolumn{2}{|c|}{6.78} & \multicolumn{2}{|c|}{7.00} & \multicolumn{2}{|c|}{11.86} \\
\hline Prob. & \multicolumn{2}{|c|}{0.5207} & 0.4 & & 0.3 & & 0.6 & & 0.2 & \\
\hline$R^{2}$ & 0.0 & & 0.0 & & 0.0 & & 0.0 & & 0.1 & \\
\hline Log Likelihood & -57 & & -40 & & -41 & & -41 & & -53 & \\
\hline & & The & etermin & ts of $m$ & estone $\mathrm{m}$ & & & & & \\
\hline & Mo & & Mo & & Mo & & Moc & 4 & Moc & 15 \\
\hline & $\mathrm{dF} / \mathrm{dx}$ & $\mathrm{z}$ & $\mathrm{dF} / \mathrm{dx}$ & $\mathrm{z}$ & $\mathrm{dF} / \mathrm{dx}$ & $\mathrm{z}$ & $\mathrm{dF} / \mathrm{dx}$ & $\mathrm{z}$ & $\mathrm{dF} / \mathrm{dx}$ & $\mathrm{z}$ \\
\hline Age & 0.009 & 0.68 & & & & & & & & \\
\hline Early Stage & & & -0.014 & -0.09 & & & & & & \\
\hline RAI & & & 0.122 & 1.44 & & & & & & \\
\hline AI & & & & & 0.048 & 1.15 & & & & \\
\hline Break Even & & & & & & & -0.082 & -0.47 & & \\
\hline Aud. Balance Sheet & & & & & & & 0.073 & 0.57 & & \\
\hline Finished Product & & & & & & & 0.202 & 1.36 & & \\
\hline Reference Customers & & & & & & & -0.072 & -0.51 & & \\
\hline Product Development & & & & & & & & & -0.043 & -0.40 \\
\hline Patents & 0.082 & 0.77 & 0.074 & 0.83 & 0.041 & 0.35 & 0.065 & 0.55 & 0.065 & 0.61 \\
\hline Independent VC & 0.114 & 0.63 & 0.253 & 1.41 & 0.114 & 0.60 & 0.123 & 0.66 & 0.115 & 0.71 \\
\hline Public VC & 0.158 & 0.76 & 0.265 & 1.13 & 0.071 & 0.32 & 0.078 & 0.35 & 0.151 & 0.77 \\
\hline Period 1 & -0.288 & -1.15 & -0.201 & -0.85 & -0.210 & -0.89 & -0.219 & -1.00 & -0.262 & -1.08 \\
\hline Period 3 & -0.053 & -0.54 & -0.117 & -1.26 & -0.081 & -0.71 & -0.087 & -0.76 & -0.095 & -0.97 \\
\hline Growth Industries & & & 0.002 & 0.09 & 0.018 & 0.12 & 0.051 & 0.37 & & \\
\hline Life Sciences & 0.152 & 0.87 & & & & & & & 0.114 & 0.70 \\
\hline Internet & 0.390 & 1.98 & & & & & & & 0.349 & 1.80 \\
\hline IT/Telecom & 0.273 & 1.70 & & & & & & & 0.271 & 1.72 \\
\hline Trad. High-Tech & 0.458 & 2.58 & & & & & & & 0.376 & 2.18 \\
\hline No of Obs. & & & & & & & 8 & & & \\
\hline Wald $/ \chi^{2}$ & & & & & & & & & & \\
\hline Prob. & & & 0.5 & & 0.8 & & 0.8 & & 0.4 & \\
\hline$R^{2}$ & 0.0 & & 0.0 & & 0.0 & & 0.0 & & 0.0 & \\
\hline Log Likelihood & -75 & & -49 & & -53 & & -51 & & -72 & \\
\hline
\end{tabular}

Notes: Probit regression with clustered standard errors at firm-level. Dependent variable is the dummy variable OTHER MILESTONE (MILESTONE MIX) which takes value one when an other milestone (milestone mix) is used with milestone financing and 0 otherwise. Marginal effects are indicated. 


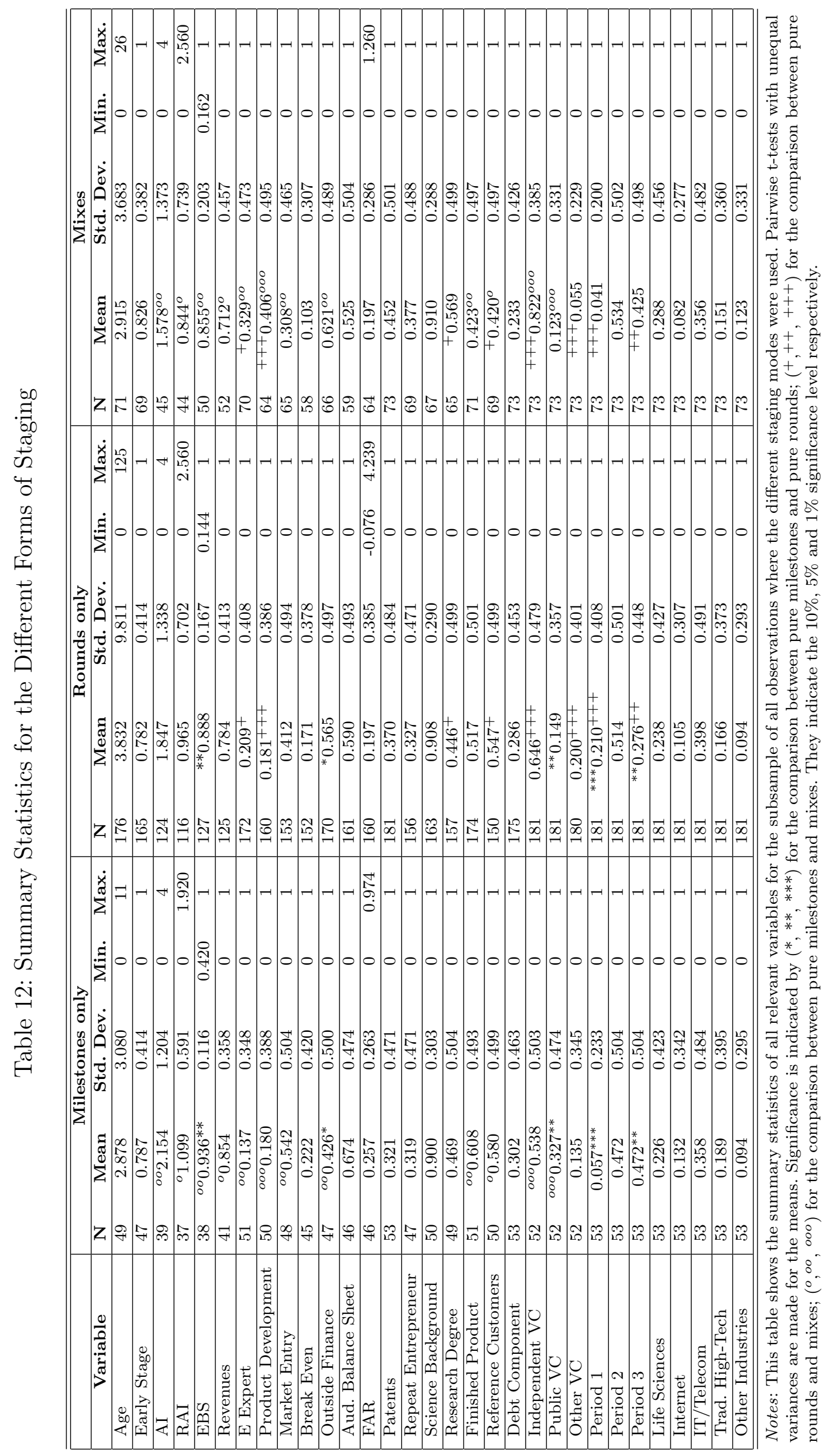


Table 13: The Determinants between Pure Milestones, Pure Rounds and Mixes (1)

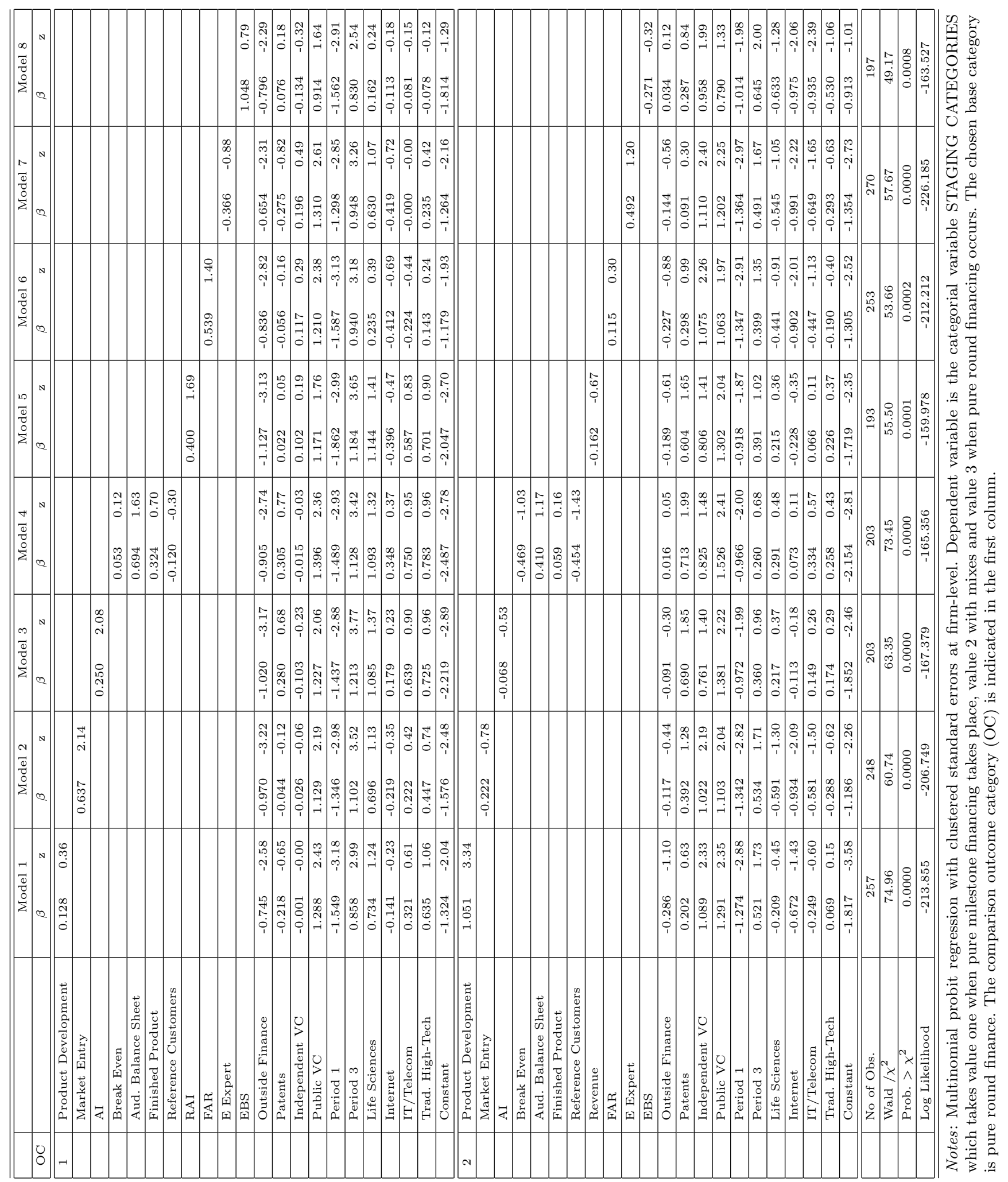


Table 14: The Determinants between Pure Milestones, Pure Rounds and Mixes (2)

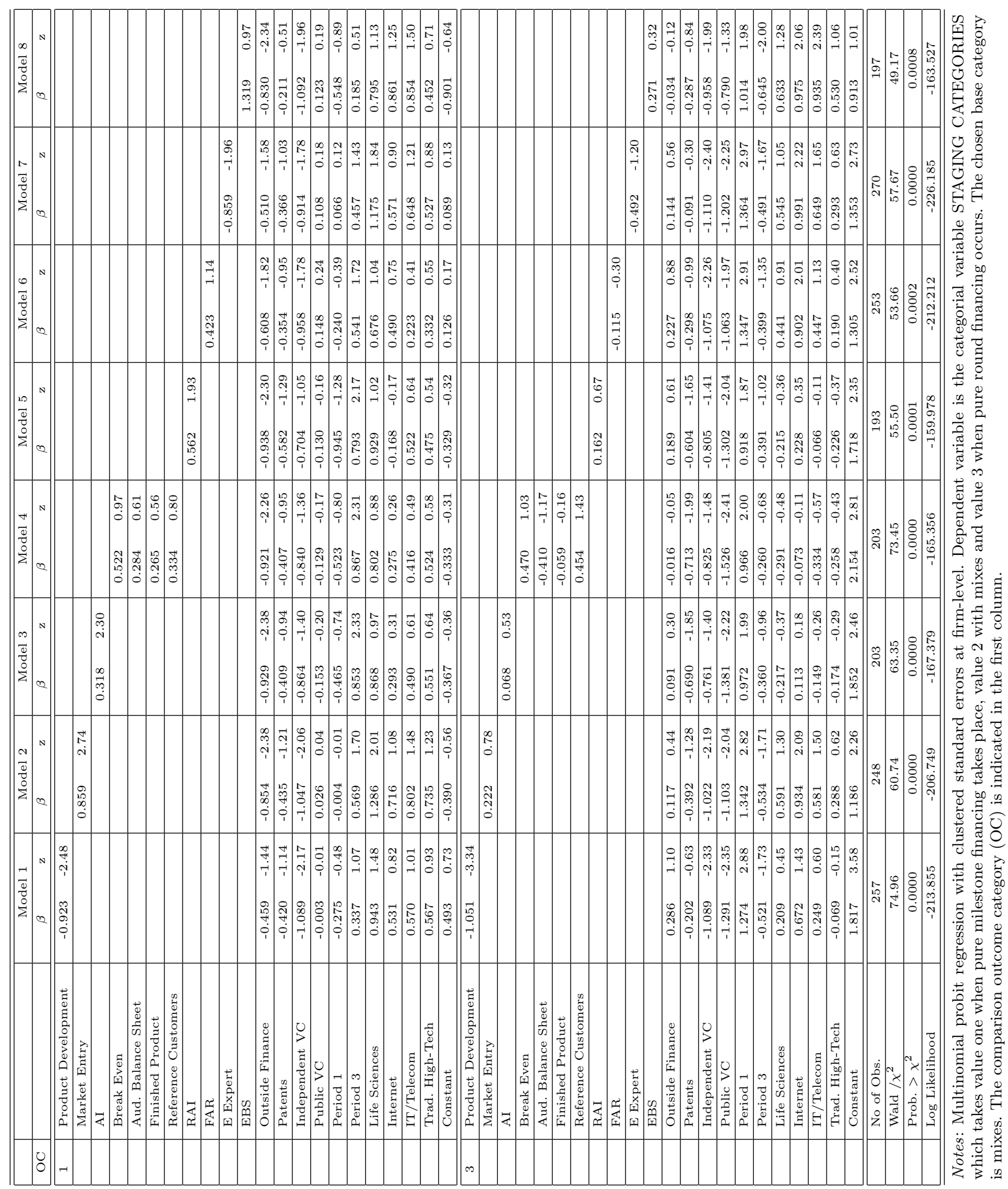

